\title{
Insights into the insect salivary gland proteome: Diet-associated changes in caterpillar labial salivary proteins
}

\author{
Khashayar Afshar ${ }^{a}$, Fitsum Fikru Dube ${ }^{a}$, Hamed S. Najafabadi ${ }^{b}$, Eric Bonneil ${ }^{c}$, Pierre Thibault $^{c}$, \\ Reza Salavati ${ }^{\mathrm{b}}$, Jacqueline C. Bede ${ }^{\mathrm{a}, *}$ \\ ${ }^{a}$ Department of Plant Science, McGill University, 21,111 Lakeshore, Ste-Anne-de-Bellevue, Qc, Canada H9X 3V9 \\ ${ }^{\mathrm{b}}$ Institute of Parasitology, McGill University, 21,111 Lakeshore, Ste-Anne-de-Bellevue, Qc, Canada H9X 3V9 \\ ${ }^{\mathrm{c}}$ Institute for Research in Immunology and Cancer, Université de Montreal, Montréal, Qc, Canada H3T 1J4
}

\section{A R T I C L E I N F O}

\section{Article history:}

Received 21 August 2012

Received in revised form 5 January 2013

Accepted 7 January 2013

Available online 23 January 2013

\section{Keywords:}

Beet armyworm

Labial salivary gland

NanoLC/ESI/MS/MS

Nutritional quality

Proteomics

Spodoptera exigua

\begin{abstract}
A B S T R A C T
The primary functio of salivary glands is fluid and protein secretion during feeding. Compared to mammalian systems, little is known about salivary protein secretion processes and the effect of diet on the salivary proteome in insect models. Therefore, the effect of diet nutritional quality on caterpillar labial salivary gland proteins was investigated using an unbiased global proteomic approach by nanoLC/ESI/ tandem MS. Caterpillars of the beet armyworm, Spodoptera exigua Hübner, were fed one of three diets: an artificial diet containing their self-selected protein to carbohydrate (p:c) ratio (22p:20c), an artificial diet containing a higher nutritional content but the same p:c ratio (33p:30c) or the plant Medicago truncatula Gaertn. As expected, most identified proteins were associated with secretory processes and not influenced by diet. However, some diet-specific differences were observed. Nutrient stress-associated proteins, such as peptidyl-propyl cis-trans isomerase and glucose-regulated protein94/endoplasmin, and glyceraldehyde 3-phosphate dehydrogenase were identified in the labial salivary glands of caterpillars fed nutritionally poor diets, suggesting a link between nutritional status and vesicular exocytosis. Heat shock proteins and proteins involved in endoplasmic reticulum-associated protein degradation were also abundant in the labial salivary glands of these caterpillars. In comparison, proteins associated with development, such as arylphorin, were found in labial salivary glands of caterpillars fed 33p:30c. These results suggest that caterpillars fed balanced or nutritionally-poor diets have accelerated secretion pathways compared to those fed a protein-rich diet.
\end{abstract}

() 2013 Elsevier Ltd. All rights reserved.
Abbreviations: BiP, binding immunoglobulin protein/glucose regulated protein GRP78; COPI, coat protein complex I; COPII, coat protein complex II; EE, early endosome; ER, endoplasmic reticulum; ERAD, endoplasmic reticulum-associated degradation; ERGIC, endoplasmic reticulum Golgi intermediate compartment; GA3PDH, glyceraldehyde 3-phosphate dehydrogenase; GOX, glucose oxidase; GRP94, glucose regulated protein 94; HSP, heat shock protein; IDGF, imaginal disc growth factor; nanoLC/ESI/MS/MS, nanoliquid chromatography/electrospray ionization/mass spectroscopy/mass spectroscopy; LE, late endosome; NCBI, National Center for Biotechnology Information; P26S4, proteasome 26 subunit 4; p97/Npl4/ Ufd1 complex, p97/nuclear protein localization 4/ubiquitin fusion degradation 1 complex; PDI, protein disulphide isomerase; PPI, peptidyl-propyl cis-trans isomerase; RPN, regulatory particle non-ATPase; TBP1, ATP-dependent TAT binding protein-1; TGN, trans-Golgi network; RACK1, receptor for activated protein C kinase; V-ATPase, vacuolar-ATPase.

* Corresponding author. Tel.: +1 5143987860 .

E-mail addresses: Khashayar.afshar@mail.mcgill.ca (K. Afshar), Fitsum. dube@mail.mcgill.ca (F.F. Dube), Hamed.shaterinajafabadi@mail.mcgill.ca (H.S. Najafabadi), Eric.bonneil@umontreal.ca (E. Bonneil), Pierre.thibault@umontreal.ca (P. Thibault), Reza.salavati@mcgill.ca (R. Salavati), Jacqueline.bede@mcgill.ca (J.C. Bede).

\section{Introduction}

Recognition that insect oral secretions (saliva and/or regurgitant) modify host plant or animal responses has lead to proteomic investigation of the salivary gland (sialome) or associated secretions (secretome). In blood-feeding insects, often vectors of disease-causing parasites, identification of salivary proteins may lead to targets for the control of transmission and/or disease (Ribeiro and Francischetti, 2003; Valenzuela et al., 2003; Ribeiro et al., 2004; Kalume et al., 2005; Arcà et al., 2007). In phloem-feeding insects, salivary recognition factors responsible for the initiation of host plant defenses have been identified (Harmel et al., 2008; Carolan et al., 2009; Cooper et al., 2010). However, given the importance of caterpillar saliva as a potential source of enzymes for the digestion and detoxification of noxious compounds as well as effectors which suppress the induction of plant defenses, few studies have focused on the caterpillar labial salivary gland and proteins involved in secretory processes (Mathews et al., 1997; 
Eichenseer et al., 1999; Musser et al., 2002a; Weech et al., 2008; Zhou et al., 2008; de la Paz Celorio-Mancera et al., 2011, 2012).

Lepidopteran larvae possess two distinct salivary organs; a pair of labial salivary glands and a pair of mandibular salivary glands (House and Ginsborg, 1985). The watery secretions of the mandibular glands contain proteins, lipids, sterols and triglycerides but litthe is known about its full composition (Felton, 2008). Recent proteomic analysis of Vanessa gonerilla caterpillar mandibular glands identified key proteins, such as lysozyme, $\alpha$-amylase, a putative chemosensory protein and sericotropin, associated with the mandibular salivary glands (de la Paz Celorio-Mancera et al., 2012). Even though the labial salivary glands of some caterpillar species, such as the silkworm, Bombyx mori, are specialized for silk production, these glands in many other caterpillar species are responsible for proteinaceous salivary secretions (Eichenseer et al., 2010). Structurally, caterpillar labial salivary glands are a pair of long, unicellular, tubular structures that fuse to form a common duct in the head region (House and Ginsborg, 1985; Parthasarathy and Gopinathan, 2005; Daimon et al., 2008). After secretory cells release enzymes, ions and water into the salivary gland lumen, ions are retaken up by the resorptive cells, and then the saliva is finally released from the labial salivary duct through a specialized organ, the spinneret (House and Ginsborg, 1985; Ali, 1997; Musser et al., 2002a). In caterpillar species whose labial glands mainly produce protein-rich saliva, important enzymes, including lysozyme, ascorbate peroxidase and glucose oxidase (GOX), in these secretions have been characterized (Mathews et al., 1997; Eichenseer et al., 1999; Liu et al., 2004; de la Paz Celorio-Mancera et al., 2011, 2012). However, in caterpillars, little is known about protein secretion processes in these glands.

Saliva formation and salivation are highly regulated processes. In human parotid cells, a number of pathways are implicated in proteinacous salivary secretion (Gorr et al., 2005). The classical secretory pathway is predominantly responsible for protein-rich secretions resulting from the exocytosis of large dense-core secretory vesicles, which may be constitutively secreted (minor) or stimulated in response to muscurinic-cholinergic and adrenergic signals. Pathways responsible for minor salivary secretions include a constitutive pathway where the secretory vesicles are derived from the trans-Golgi network and a regulated pathway where further maturation of the secretory granules occurs. In the main classical secretory pathway, proteins destined for salivary secretions through the trans-Golgi network and/or dense core secretory vesicles are synthesized by ribosomes and translocated into the ER lumen through the Sec translocon complex cotranslationally or, less commonly, post-translationally (Kim et al., 2006; Gasser et al., 2008; Brunner et al., 2009). In the ER lumen, nascent polypeptide chains follow one of two major pathways (Braakman and Bulleid, 2011). One route involves the binding of the growing polypeptide chain to the Binding immunoglobulin Protein/Glucose-regulated Protein $78 \mathrm{kD} /$ Heat Shock Protein 70 (BiP/GrP78/HSP70) followed by formation of disulfide bonds by a protein disulfide isomerase (PDI). For glycoproteins, $N$-linked monoglycans are recognized by the ERp57/calreticulin complex or canexin (Ellgaard and Helenius, 2003; Frickel et al., 2004). Only upon proper folding are proteins transported to the trans-Golgi network. Misfolded proteins remain bound to BiP which leads to retrograde translocation into the cytosol and proteasome-mediated protein degradation through the ER-associated degradation (ERAD) pathway (Nishikawa et al., 2001; Ryoo and Steller, 2007; Bagola et al., 2011). From the Golgi, a number of cellular pathways lead to secretory granular biogenesis and the extracellular release of proteinaceous material (Burgoyne and Morgan, 2003; Nashida et al., 2004; Gorr et al., 2005). The exact mechanism for the formation of dense-core granules from the trans-Golgi network is not fully understood but proposed models include the vesicular transport or the cisternal maturation or the cisternal progenitor models (Gorr et al., 2005; Pfeffer, 2010).

In response to adrenergic or muscarinic-cholinergic signals, secretory granules in salivary glands are guided to the plasma membrane on microtubule rails driven by kinesin protein motors (Hirokawa et al., 1998; Nashida et al., 2004). At the plasma membrane, granules transport then switches to an actin filament (microfilaments)/myosin system (Valentijn et al., 1999). Release of granule contents into the gland lumen may involve a rapid fusion and reclosure of the fusion pore (kiss-and-run model) or full fusion and emptying of the granule with the plasma membrane followed by retrieval involving a clathrin/dyamin-associated mechanism (Harata et al., 2006).

In diverse insect species, diet affects either salivary protein levels or activity or secretion. In female mosquitoes, blood-feeding rapidly results in dynamic changes to the salivary gland transcriptome (Das et al., 2010). Salivary secretions of the Russian wheat aphid, Diuraphis noxia, were also affected by diet (Cooper et al., 2010). In Noctuid caterpillars, a number of salivary enzymes have shown diet-specific gene expression and activity (Liu et al., 2004; Afshar et al., 2010). Mid- $5^{\text {th }}$ instar corn earworm, Helicoverpa $z e a$, salivary glands have higher expression of the gene encoding lysozyme when caterpillars feed on cotton or tomato compared to tobacco plants (Liu et al., 2004). The effect of diet on caterpillar labial salivary GOX activity is of particular interest since GOX potentially negatively affects the plant's ability to mount an appropriate defense response (Eichenseer et al., 1999, 2010; Musser et al., 2002a; Weech et al., 2008). GOX catalyses the oxidation of glucose and the activity of this enzyme have been found to increase when caterpillars were fed carbohydrate-based diets, lending credibility to the idea that this enzyme may be a pre-ingestive mechanism to balance dietary sugar intake as excess carbohydrates have a negative impact on insect mortality (Felton, 1996; WarbrickSmith et al., 2006; Babic et al., 2008). Caterpillars often exhibit a self-selective feeding behavior to balance their diet, in particular, the intake of protein to digestible carbohydrate $(\mathrm{p}: \mathrm{c})$ ratio, which leads to optimal performance (growth, development, fecundity) of the insect (Waldbauer and Friedman, 1991; Lee et al., 2002; Merkx-Jacques et al., 2008); the self-selected ratio of Spodoptera exigua Hübner caterpillars is 22p:20c (Merkx-Jacques et al., 2008). By altering the ratio and levels of p:c, Afshar et al. (2010) showed that labial salivary gland SeGOX gene expression reflects glucose levels, but enzyme activity is also influenced by the nutritional protein content such that enzyme activity was highest when caterpillars were fed a carbohydrate- and protein-rich diet (Afshar et al., 2010). This suggests that there is both transcriptional and post-translational regulation of GOX. However, an alternative explanation is that on the high carbohydrate diet, GOX protein levels and salivary secretions increase but on a high protein diet, a feedback loop inhibits secretory granule exocytosis leading to the accumulation of labial salivary digestive enzymes.

In many insect models, diet and, in particular, nutritional quality, alters salivary enzyme gene expression, activity and secretion (Liu et al., 2004; Merkx-Jacques and Bede, 2005; Hu et al., 2008; Afshar et al., 2010; Das et al., 2010). This study examined the role of diet on caterpillar salivary secretion machinery by using a global proteomic approach. Three diets were chosen: the plant Medicago truncatula L. and two artificial diets that varied in their protein and carbohydrate levels, while maintaining the same protein to carbohydrate $(\mathrm{p}: \mathrm{c})$ ratio. $M$. truncatula was chosen as it is eaten by caterpillars of the beet armyworm, S. exigua, a generalist Noctuid pest. The self-selected p:c ratio by these caterpillars is 22p:20c (Merkx-Jacques et al., 2008). Therefore, the two artificial diets (22p:20c and 33p:30c) represent this ratio; previous studies have shown SeGOX gene expression and enzyme activity is higher on 33p:30c (Afshar et al., 2010). S. exigua caterpillars were reared 
from $3^{\text {rd }}$ instars on the respective diets. Soluble proteins from labial salivary glands of actively feeding 4th instar caterpillars were subject to global proteomic analysis by nanoLC/ESI/tandem MS. Many of caterpillar labial salivary proteins identified play a role in protein secretion. Diet-specific differences were observed with nutrient-stress related proteins, such as peptidyl-propyl cis-trans isomerase (PPI) and glucose-regulated protein94 (GRP94/endoplasmin), identified in the nutrient-poor diets, 22p:20c and $M$. truncatula (Lee, 2001; Gupta and Tuteja, 2011). In comparison, proteins highly associated with nutritional allometry, such as imaginal disc growth factor (IDGF), and developmental processes were identified in the labial salivary glands of caterpillars fed the proteinrich diet, 33p:30c (Shingleton et al., 2008).

\section{Materials and methods}

\subsection{Chemicals}

Unless otherwise specified, all chemicals were obtained from Sigma-Aldrich Chemical Co.

\subsection{Caterpillar colony}

Beet armyworm, S. exigua, eggs were obtained from AgriPest and reared for multiple generations $(>20)$ at $28.5^{\circ} \mathrm{C}$ under a $16: 8$ (L:D) photoperiod. Colony caterpillars were reared on a meridic wheat-germ based diet (Bio-Serv). Adults were allowed to mate and lay eggs to maintain the colony.

\subsection{Diets}

\subsubsection{Plant diet}

Seeds of the barrel medic, M. truncatula (Gaertn.) cv. Jemalong A17, were scarified in sulfuric acid and germinated on moist filter paper. Germinated seedlings were planted in pasteurized soil $\left(80^{\circ} \mathrm{C}\right.$ for $\left.2 \mathrm{~h}\right)$ and grown in a phytorium chamber under the following conditions: $260 \mathrm{~m} \mathrm{Em}^{-2} \mathrm{~s}^{-1}, 22^{\circ} \mathrm{C}$ under a $16: 8$ (L:D) photoperiod. Plants were fertilized three times per week using dilute $\mathrm{N}$ :P:K fertilizer. Six-week old plants were used in the herbivore studies; these plants have an approximate p:c ratio of 16.6:27.7 (Merkx-Jacques, personnel comm.).

\subsubsection{Artificial diet}

Artificial diets with set $\mathrm{p}: \mathrm{c}$ ratios were prepared according to Simpson and Abisgold (1985). The protein source was a 3:1:1 ratio of casein (bovine milk, Bio-Serv), peptone and albumen (egg-white, Bio-Serv) which represents an amino acid composition similar to wheat seedlings (Lee et al., 2003). The carbohydrate source was glucose and the non-digestible filler was cellulose. The diets made up such that the ratio of protein:glucose:cellulose was 22:20:44 for 22p:20c and 33:20:23 for 33p:30c. Components of all diets were: $0.55 \%$ cholesterol (Bio-Serv) solubilized in $0.5 \%$ linoleic acid, $2.5 \%$ Wesson's salts, $1 \%$ ascorbate (vitamin C), $0.5 \%$ choline chloride, $0.5 \%$ sorbic acid, $0.35 \%$ methyl paraben (Bio-Serv), $0.285 \%$ thiamine (vitamin $\mathrm{B}_{1}$ ), $0.285 \%$ riboflavin (vitamin $\mathrm{B}_{2}$ ), $1.14 \%$ nicotinamide (vitamin $B_{3}$ ), $0.285 \%$ pyridoxine (vitamin $B_{6}$ ), $0.285 \%$ folic acid (vitamin $\mathrm{B}_{9}$ ), 2.85\% myo-inositol, $0.57 \%$ calcium panthothenic acid (vitamin $\mathrm{B}_{5}$ ), $0.285 \%$ p-aminobenzoic acid and $0.011 \%$ biotin (vitamin $B_{7}$ ) (Bio-Serv). Diets were prepared in $2 \%$ agar.

\subsection{Experimental design}

To ensure uniform growth and development, S. exigua caterpillars were reared until early $3^{\text {rd }}$ instars on a wheat germ-based diet (Bio-Serv) and then transferred to the treatment diets: M. truncatu- la plants or $\mathrm{AD} 22 \mathrm{p}: 20 \mathrm{c}$ or $\mathrm{AD} 33 \mathrm{p}: 30 \mathrm{c}$. Labial salivary glands were dissected from actively feeding mid $-4^{\text {th }}$ instar caterpillars. Cold anaesthetized insects were placed ventrally and the labial salivary glands removed and rinsed in sterile Nathanson's saline (150 mM $\mathrm{NaCl}, 3 \mathrm{mM} \mathrm{KCl}, 3 \mathrm{mM} \mathrm{CaCl}, 10 \mathrm{mM} \mathrm{N}$-tris (hydroxymethyl) methyl-2-aminoethane sulfonic acid, $20 \mathrm{mM} \mathrm{MgCl}_{2}$ ) containing $10 \%$ general proteinase inhibitor (Christensen et al., 1991). One hundred salivary glands were pooled and stored at $-80^{\circ} \mathrm{C}$ until homogenization. The experiment on each diet was independently repeated trice. Each analysis represents both the cellular and the salivary gland lumen content. Protein concentration in labial salivary gland homogenates were measured by the Bradford assay and protein concentration standardized across all samples (Bradford, 1976)

\subsection{NanoLC-ESI-MS/MS}

Proteins were separated by electrophoresis on a non-denaturing 4-15\% gradient gel and for each lane, 3 gel pieces were removed for analysis by nanoLC-ESI-MS/MS. Following destaining of the gel slices in 50\% methanol, the gel was placed in $10 \mathrm{mM}$ dithiothreitol for $1 \mathrm{~h}$ at $56^{\circ} \mathrm{C}$ to reduce protein disulfide groups. The gel was then incubated in $55 \mathrm{mM}$ chloroacetamide for $1 \mathrm{~h}$ at room temperature to alkylate the proteins. After washing in $50 \mathrm{mM}$ ammonium bicarbonate, gel pieces were placed in $100 \%$ acetonitrile (ACN). Proteins were digested using $1700 \mathrm{U}$ trypsin in $50 \mathrm{mM}$ ammonium biocarbonate for $8 \mathrm{~h}$ at $37^{\circ} \mathrm{C}$. Peptides were then extracted in $90 \% \mathrm{ACN}$ in $0.5 \mathrm{M}$ urea. Samples were dried in a speed-vac and then resolubilized in $5 \%$ ACN in $0.2 \%$ formic acid (FA). Separation of peptides was performed using a nano liquid chromatography-2-dimensional system (Eksingent) using a $C_{18}$ column $(150 \mu \mathrm{m} \times 10 \mathrm{~cm})$. A gradient from 10 to $60 \%$ ACN in $0.2 \%$ FA over $1 \mathrm{~h}$ at a flow rate of $600 \mathrm{~nL} / \mathrm{min}$ was used to elute peptides. After peptide separation by LC-chromatography, peptides entered the LTQ-Orbitrap mass spectrometer (ThermoScientific). Each full mass spectrum (MS) acquired at a resolution of 60,000 was followed by three MS/MS spectrum, where the three most abundantly multiple charged ions were selected for MS/MS sequencing. Peptide sequences were acquired using collision-induced dissociation in the linear ion trap.

\subsection{Data analysis}

Since the $S$. exigua genome has not been fully sequenced, protein identification was based on peptide comparison to the nonredundant NCBI dataset using Mascot version 2.2 (Matrix Science). Tolerance parameters were set at 0.03 and $0.5 \mathrm{Da}$ for the precursor and fragment ions, respectively. As well, the following variable modifications were set: oxidation (M), deamination (NQ), phosphor (STY), nitroxyl (C), sulfide (C), carbamidomethyl, (C), 4-ONE (C) and sulfo (C). The high degree of redundancy present in the dataset which was reduced by NoRed, an algorithm identifies the optimal subset of proteins in the mass spectroscopy analysis to allow the minimum number of proteins to be identified (http://webpages.mcgill.ca/staff/Group2/rsalav/web/Software/NoRed/NoRed. zip). Protein identification was based on the detection of two or more peptides.

Non-redundant proteins were quantified based on the protein score. The data was normalized to ensure that the total number of peptides identified in each mass specrophotometric run will not affect the final analysis. To be considered present in the salivary glands, a protein needed to be identified in all three independent biological replications (Table 1). Proteomic data is available in Supplemental Table 1 and deposited in the proteomics identification database (PRIDE; http://www.ebi.ac.uk/pride). 
Table 1

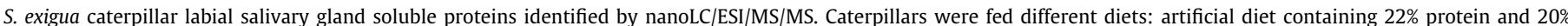

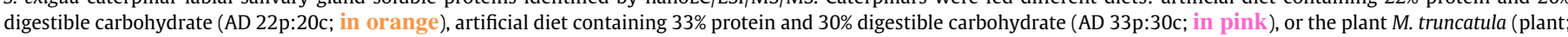

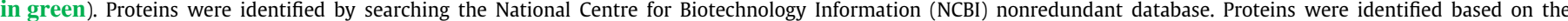
presence of $>2$ diagnostic peptides and needed to be present in all three independent experimental replications.

\begin{tabular}{|c|c|c|c|c|}
\hline $\begin{array}{c}\text { NCBI accession } \\
\text { number }\end{array}$ & Protein description & & Diet & \\
\hline & & $22 \mathrm{p}: 20 \mathrm{c}$ & $33 \mathrm{p}: 30 \mathrm{c}$ & Medicago \\
\hline \multicolumn{5}{|l|}{$\begin{array}{l}\text { Protein secretion/exo- } \\
\text { and endocytosis }\end{array}$} \\
\hline gi| 12025459 & $\begin{array}{l}\text { Protein disulfide isomerase } \\
\text { (Bombyx mori) }\end{array}$ & $\begin{array}{c}\mathrm{AD} \\
22 \mathrm{p}: 20 \mathrm{c}\end{array}$ & $\begin{array}{c}\mathrm{AD} \\
33 \mathrm{p}: 30 \mathrm{c}\end{array}$ & plant \\
\hline gi 62241290 & $\begin{array}{l}\text { Protein disulfide isomerase }(B . \\
\text { mori) ERp } 57\end{array}$ & $\begin{array}{c}\mathrm{AD} \\
22 \mathrm{p}: 20 \mathrm{c}\end{array}$ & $\begin{array}{c}\mathrm{AD} \\
33 \mathrm{p}: 30 \mathrm{c}\end{array}$ & plant \\
\hline gi| 15077034 & Calcineurin A (B. mori) & $\begin{array}{c}\mathrm{AD} \\
22 \mathrm{p}: 20 \mathrm{c}\end{array}$ & $\begin{array}{c}\mathrm{AD} \\
33 \mathrm{p}: 30 \mathrm{c}\end{array}$ & plant \\
\hline gi 17826933 & Calreticulin (Galleria mellonella) & & $\begin{array}{c}\mathrm{AD} \\
33 \mathrm{p}: 30 \mathrm{c}\end{array}$ & plant \\
\hline gi|52630957 & $\begin{array}{l}\text { Probably transport protein Sec61 } \\
\text { a-subunit (Toxoptera citricida) }\end{array}$ & $\begin{array}{c}\mathrm{AD} \\
22 \mathrm{p}: 20 \mathrm{c}\end{array}$ & $\begin{array}{c}\text { AD } \\
33 \mathrm{p}: 30 \mathrm{c}\end{array}$ & plant \\
\hline gi|7271162 & $\begin{array}{l}\text { Putative Sec } 23 \text { protein } \\
\text { (Drosophila melanogaster) }\end{array}$ & $\begin{array}{c}\mathrm{AD} \\
22 \mathrm{p}: 20 \mathrm{c}\end{array}$ & & plant \\
\hline gi|2499773 & $\begin{array}{l}\text { FK506-binding nuclear protein; } 46 \\
\text { kDa FK506-binding nuclear } \\
\text { protein (Peptidyl-prolyl cis-trans } \\
\text { isomerase) (PPIase) (Rotamase) }\end{array}$ & & & plant \\
\hline gi|13991907 & $\begin{array}{l}\text { Receptor for activated protein } \\
\text { kinase C (RACK1) (Heliothis } \\
\text { virescens) }\end{array}$ & $\begin{array}{c}\mathrm{AD} \\
22 \mathrm{p}: 20 \mathrm{c}\end{array}$ & $\begin{array}{c}\mathrm{AD} \\
33 \mathrm{p}: 30 \mathrm{c}\end{array}$ & plant \\
\hline gi|7722 & $\begin{array}{l}\text { Clathrin heavy chain }(D . \\
\text { melanogaster })\end{array}$ & $\begin{array}{c}\text { AD } \\
22 \mathrm{p}: 20 \mathrm{c}\end{array}$ & & plant \\
\hline gi|58864724 & $\begin{array}{l}\text { Putative annexin IX-A (Manduca } \\
\text { sexta) }\end{array}$ & & $\begin{array}{c}\mathrm{AD} \\
33 \mathrm{p}: 30 \mathrm{c}\end{array}$ & \\
\hline \multicolumn{5}{|l|}{$\begin{array}{l}\text { GTPase and } \\
\text { associated proteins }\end{array}$} \\
\hline gi| 17862730 & $\begin{array}{l}\text { LD46767p (D. melanogaster); } \\
\text { GDI }\end{array}$ & $\begin{array}{c}\mathrm{AD} \\
22 \mathrm{p}: 20 \mathrm{c}\end{array}$ & $\begin{array}{c}\text { AD } \\
33 \mathrm{p}: 30 \mathrm{c}\end{array}$ & plant \\
\hline gi|53830716 & $\begin{array}{l}\text { Putative Rab7 (Oncometopia } \\
\text { nigricans) }\end{array}$ & & $\begin{array}{c}\text { AD } \\
33 \mathrm{p}: 30 \mathrm{c}\end{array}$ & \\
\hline \multicolumn{5}{|l|}{$\begin{array}{l}\text { Heat shock proteins } \\
\text { (HSP; chaperonins) }\end{array}$} \\
\hline gi|56378321 & Small HSP 21.4 (B. mori) & & $\begin{array}{c}\mathrm{AD} \\
33 \mathrm{p}: 30 \mathrm{c}\end{array}$ & \\
\hline gi 66547450 & $\begin{array}{l}\text { HSP 60, mitochondrial-associated } \\
\text { (Apis mellifera) }\end{array}$ & $\begin{array}{c}\mathrm{AD} \\
22 \mathrm{p}: 20 \mathrm{c}\end{array}$ & $\begin{array}{c}\mathrm{AD} \\
33 \mathrm{p}: 30 \mathrm{c}\end{array}$ & plant \\
\hline gi| 2738077 & HSP 60 & $\begin{array}{c}\mathrm{AD} \\
22 \mathrm{p}: 20 \mathrm{c}\end{array}$ & $\begin{array}{c}\mathrm{AD} \\
33 \mathrm{p}: 30 \mathrm{c}\end{array}$ & plant \\
\hline gi|27260894 & $\begin{array}{l}\text { HSP cognate } 70 \text { protein } \\
\text { (Spodoptera frugiperda) }\end{array}$ & $\begin{array}{c}\mathrm{AD} \\
22 \mathrm{p}: 20 \mathrm{c}\end{array}$ & $\begin{array}{c}\text { AD } \\
33 \mathrm{p}: 30 \mathrm{c}\end{array}$ & plant \\
\hline gi|2921217 & HSP 70 (Beroe ovata) & $\begin{array}{c}\mathrm{AD} \\
22 \mathrm{p}: 20 \mathrm{c}\end{array}$ & $\begin{array}{c}\mathrm{AD} \\
33 \mathrm{p}: 30 \mathrm{c}\end{array}$ & plant \\
\hline gi|431201 & $\begin{array}{l}\text { HSP 70; heat shock protein HSP70 } \\
\text { (Pleurodeles waltl) }\end{array}$ & $\begin{array}{c}\text { AD } \\
22 \mathrm{p}: 20 \mathrm{c}\end{array}$ & $\begin{array}{c}\text { AD } \\
33 p: 30 c\end{array}$ & plant \\
\hline gi|2352599 & $\begin{array}{l}\text { HSP } 82 \mathrm{Kd} \text { (Drosophila } \\
\text { persimilis) }\end{array}$ & $\begin{array}{c}\mathrm{AD} \\
22 \mathrm{p}: 20 \mathrm{c}\end{array}$ & $\begin{array}{c}\mathrm{AD} \\
33 \mathrm{p}: 30 \mathrm{c}\end{array}$ & plant \\
\hline gi|157018473 & $\begin{array}{l}\text { AGAP010691-PA (Anopheles } \\
\text { gambia) HSP-90 }\end{array}$ & & $\begin{array}{c}\text { AD } \\
33 p: 30 c\end{array}$ & plant \\
\hline gi| 110758921 & $\begin{array}{l}\text { Endoplasmin-like isoform } 1 \text { ( } A \text {. } \\
\text { mellifera) GRP94 }\end{array}$ & $\begin{array}{c}\mathrm{AD} \\
22 \mathrm{p}: 20 \mathrm{c}\end{array}$ & & \\
\hline \multicolumn{5}{|l|}{ Protein degradation } \\
\hline gi| 159162145 & Ubiquitin & $\begin{array}{c}\mathrm{AD} \\
22 \mathrm{p}: 20 \mathrm{c}\end{array}$ & $\begin{array}{c}\mathrm{AD} \\
33 \mathrm{p}: 30 \mathrm{c}\end{array}$ & plant \\
\hline gi|463363 & $\begin{array}{l}\text { Ubiquitin (Stephanodiscus } \\
\text { yellowstonensis) }\end{array}$ & $\begin{array}{c}\text { AD } \\
22 \mathrm{p}: 20 \mathrm{c}\end{array}$ & $\begin{array}{c}\text { AD } \\
33 \mathrm{p}: 30 \mathrm{c}\end{array}$ & plant \\
\hline
\end{tabular}




\begin{tabular}{|c|c|c|c|c|}
\hline gi|4574740 & $\begin{array}{l}\text { ATP-dependent Tat-binding } \\
\text { protein-1 (D. melanogaster) } 26 \mathrm{~S} \\
\text { proteasome regulatory subunit }\end{array}$ & $\begin{array}{c}\mathrm{AD} \\
22 \mathrm{p}: 20 \mathrm{c}\end{array}$ & & plant \\
\hline gi|1066065 & $\begin{array}{l}\text { P26S4 Proteasome regulatory } \\
\text { subunit 4-like protein }(D . \\
\text { melanogaster })\end{array}$ & $\begin{array}{c}\mathrm{AD} \\
22 \mathrm{p}: 20 \mathrm{c}\end{array}$ & & plant \\
\hline gi| 55233608 & $\begin{array}{l}\text { Proteome subunit RPN2 ( } D . \\
\text { melanogaster })\end{array}$ & $\begin{array}{c}\mathrm{AD} \\
22 \mathrm{p}: 20 \mathrm{c}\end{array}$ & & plant \\
\hline gi| 312375012 & $\begin{array}{l}\text { Hypothetical protein AND_15223 } \\
\text { (Anopheles darlingi) } 26 \mathrm{~S} \\
\text { proteasome regulatory complex }\end{array}$ & $\begin{array}{c}\mathrm{AD} \\
22 \mathrm{p}: 20 \mathrm{c}\end{array}$ & & plant \\
\hline gi 157015594 & $\begin{array}{l}\text { AGAP005630-PA (A. gambia) } \\
\text { Protein processing } \\
\text { (p97/Ufd1/Np14) complex }\end{array}$ & $\begin{array}{c}\mathrm{AD} \\
22 \mathrm{p}: 20 \mathrm{c}\end{array}$ & & plant \\
\hline \multicolumn{5}{|c|}{ V-type ATPases } \\
\hline gi 12585497 & $\begin{array}{l}\text { Vacuolar-type proton ATPase } \\
\text { subunit H }\end{array}$ & $\begin{array}{c}\mathrm{AD} \\
22 \mathrm{p}: 20 \mathrm{c}\end{array}$ & $\begin{array}{c}\mathrm{AD} \\
33 \mathrm{p}: 30 \mathrm{c}\end{array}$ & plant \\
\hline gi| 198149765 & $\begin{array}{l}\text { F0/F1 ATP synthase; GA } 18845 \\
(\text { Drosophila pseudoobscura) }\end{array}$ & $\begin{array}{c}\mathrm{AD} \\
22 \mathrm{p}: 20 \mathrm{c}\end{array}$ & $\begin{array}{c}\mathrm{AD} \\
33 \mathrm{p}: 30 \mathrm{c}\end{array}$ & plant \\
\hline gi|24583988 & $\begin{array}{l}\text { VHA } 68-2 \text { isoform } \mathrm{C}(D . \\
\text { melanogaster })\end{array}$ & $\begin{array}{c}\mathrm{AD} \\
22 \mathrm{p}: 20 \mathrm{c}\end{array}$ & $\begin{array}{c}\text { AD } \\
33 p: 30 c\end{array}$ & plant \\
\hline gi|37781636 & $\begin{array}{l}\text { Vacuolar proton ATPase } \beta \text {-subunit } \\
\text { (Artemia fransiscana) }\end{array}$ & $\begin{array}{c}\mathrm{AD} \\
22 \mathrm{p}: 20 \mathrm{c}\end{array}$ & & \\
\hline gi|46909243 & F1 ATP synthase $\beta$-subunit & $\begin{array}{c}\mathrm{AD} \\
22 \mathrm{p}: 20 \mathrm{c}\end{array}$ & $\begin{array}{c}\mathrm{AD} \\
33 \mathrm{p}: 30 \mathrm{c}\end{array}$ & plant \\
\hline gi 12585498 & $\begin{array}{l}\text { V-type Vacuolar proton ATPase } \\
\text { subunit C (Manduca sexta) }\end{array}$ & $\begin{array}{c}\mathrm{AD} \\
22 \mathrm{p}: 20 \mathrm{c}\end{array}$ & $\begin{array}{c}\mathrm{AD} \\
33 \mathrm{p}: 30 \mathrm{c}\end{array}$ & \\
\hline \multicolumn{5}{|c|}{ 14-3-3 proteins } \\
\hline gi|52001207 & $\begin{array}{l}\text { 14-3-3 protein (Fundulus } \\
\text { heteroclitus) }\end{array}$ & $\begin{array}{c}\mathrm{AD} \\
22 \mathrm{p}: 20 \mathrm{c}\end{array}$ & & \\
\hline gi|332814474 & $\begin{array}{l}\text { PREDICTED: similar to epsilon } \\
\text { isoform of } 14-3-3 \text { protein (Pan } \\
\text { troglodytes) }\end{array}$ & $\begin{array}{c}\mathrm{AD} \\
22 \mathrm{p}: 20 \mathrm{c}\end{array}$ & $\begin{array}{c}\mathrm{AD} \\
33 \mathrm{p}: 30 \mathrm{c}\end{array}$ & \\
\hline \multicolumn{5}{|l|}{ Other } \\
\hline gi| 10801564 & $\begin{array}{l}\text { Imaginal disc growth factor-like } \\
\text { protein (B. mori) }\end{array}$ & $\begin{array}{c}\mathrm{AD} \\
22 \mathrm{p}: 20 \mathrm{c}\end{array}$ & $\begin{array}{c}\mathrm{AD} \\
33 \mathrm{p}: 30 \mathrm{c}\end{array}$ & plant \\
\hline gi|47607477 & $\begin{array}{l}\text { Imaginal disc growth factor (Pieris } \\
\text { rapae) }\end{array}$ & & $\begin{array}{c}\mathrm{AD} \\
33 \mathrm{p}: 30 \mathrm{c}\end{array}$ & \\
\hline gi|3318722 & Trypsin inhibitor & $\begin{array}{c}\mathrm{AD} \\
22 \mathrm{p}: 20 \mathrm{c}\end{array}$ & $\begin{array}{c}\mathrm{AD} \\
33 \mathrm{p}: 30 \mathrm{c}\end{array}$ & plant \\
\hline gi|44886002 & $\begin{array}{l}\text { Ribonuclease L inhibitor homolog } \\
\text { (B. mori) }\end{array}$ & $\begin{array}{c}\text { AD } \\
22 p: 20 c\end{array}$ & $\begin{array}{c}\text { AD } \\
33 p: 30 c\end{array}$ & plant \\
\hline gi|47216201 & $\begin{array}{l}\text { Unnamed protein product } \\
\text { (Tetraodon nigroviridis) }\end{array}$ & $\begin{array}{c}\mathrm{AD} \\
22 \mathrm{p}: 20 \mathrm{c}\end{array}$ & $\begin{array}{c}\text { AD } \\
33 p: 30 c\end{array}$ & plant \\
\hline gi|56462182 & $\begin{array}{l}\text { Hypothetical protein } 6 \text { (Lonomia } \\
\text { obliqua) }\end{array}$ & $\begin{array}{c}\mathrm{AD} \\
22 \mathrm{p}: 20 \mathrm{c}\end{array}$ & $\begin{array}{c}\mathrm{AD} \\
33 \mathrm{p}: 30 \mathrm{c}\end{array}$ & \\
\hline gi| 341904220 & $\begin{array}{l}\text { Hypothetical protein } \\
\text { caebren_25396 (Caenorhabditis } \\
\text { brenneri) }\end{array}$ & & $\begin{array}{c}\text { AD } \\
33 \mathrm{p}: 30 \mathrm{c}\end{array}$ & \\
\hline gi|198151038 & $\begin{array}{l}\text { GA28352 (Drosophila } \\
\text { pseudoobscura pseudoobscura) }\end{array}$ & $\begin{array}{c}\text { AD } \\
22 \mathrm{p}: 20 \mathrm{c}\end{array}$ & & \\
\hline gi|5869989 & $\begin{array}{l}\text { Arylphorin subunit (Spodoptera } \\
\text { litura) }\end{array}$ & & $\begin{array}{c}\mathrm{AD} \\
33 \mathrm{p}: 30 \mathrm{c}\end{array}$ & \\
\hline gi|38260562 & Thiol peroxiredoxin (B.mori) & & $\begin{array}{c}\mathrm{AD} \\
33 \mathrm{p}: 30 \mathrm{c}\end{array}$ & \\
\hline
\end{tabular}




\section{Table 1 (continued)}

\begin{tabular}{|c|c|c|c|c|}
\hline \multicolumn{5}{|l|}{ Cytoskeleton } \\
\hline gi|16517097 & $\beta$-Tubulin & $\begin{array}{c}\text { AD } \\
22 p: 20 c\end{array}$ & $\begin{array}{c}\mathrm{AD} \\
33 \mathrm{p}: 30 \mathrm{c}\end{array}$ & plant \\
\hline gi|4140272 & Tubulin & $\begin{array}{c}\text { AD } \\
22 \mathrm{p}: 20 \mathrm{c}\end{array}$ & $\begin{array}{c}\text { AD } \\
33 \mathrm{p}: 30 \mathrm{c}\end{array}$ & plant \\
\hline gi|22450696 & $\alpha$-Tubulin IV & $\begin{array}{c}\text { AD } \\
22 \mathrm{p}: 20 \mathrm{c}\end{array}$ & & \\
\hline gi| 87248487 & $\begin{array}{l}\text { Microtubule-assocated protein } \\
\text { RP/EB family member } 3 \text { (Bombyx } \\
\text { mori) }\end{array}$ & & $\begin{array}{c}\mathrm{AD} \\
33 \mathrm{p}: 30 \mathrm{c}\end{array}$ & \\
\hline gi|62956591 & $\begin{array}{l}\beta \text {-actin: cell motility (Vanessa } \\
\text { cardui) }\end{array}$ & $\begin{array}{c}\mathrm{AD} \\
22 \mathrm{p}: 20 \mathrm{c}\end{array}$ & $\begin{array}{c}\mathrm{AD} \\
33 \mathrm{p}: 30 \mathrm{c}\end{array}$ & plant \\
\hline gi| 61105584 & $\begin{array}{l}\beta \text {-actin: cell motility } \\
\text { (Palaemonetes pugio) }\end{array}$ & $\begin{array}{c}\mathrm{AD} \\
22 \mathrm{p}: 20 \mathrm{c}\end{array}$ & $\begin{array}{c}\text { AD } \\
33 \mathrm{p}: 30 \mathrm{c}\end{array}$ & \\
\hline gi|3879477 & Actin (C. elegans) & & $\begin{array}{c}\mathrm{AD} \\
33 \mathrm{p}: 30 \mathrm{c}\end{array}$ & \\
\hline gi $\mid 10270$ & Kinesin heavy chain (Sea urchin) & & & plant \\
\hline gi|76789674 & $\begin{array}{l}\text { Tropomyosin- } 1 \text {, isoforms } 9 \mathrm{~A} / \mathrm{A} / \mathrm{B} \\
\text { (D. melanogaster) }\end{array}$ & & $\begin{array}{c}\mathrm{AD} \\
33 \mathrm{p}: 30 \mathrm{c}\end{array}$ & \\
\hline gi|328784401 & $\begin{array}{l}\text { Moesin/ezrin/radixin homolog } 1 \\
\text { (A. mellifera) }\end{array}$ & $\begin{array}{c}\mathrm{AD} \\
22 \mathrm{p}: 20 \mathrm{c}\end{array}$ & $\begin{array}{c}\mathrm{AD} \\
33 \mathrm{p}: 30 \mathrm{c}\end{array}$ & plant \\
\hline \multicolumn{5}{|c|}{ mRNA-associated } \\
\hline gi|54635929 & $\begin{array}{l}\text { GA } 18673 \text { (D. pseudoobscura } \\
\text { pseudoobscura) }\end{array}$ & $\begin{array}{c}\mathrm{AD} \\
22 \mathrm{p}: 20 \mathrm{c}\end{array}$ & & plant \\
\hline gi|29841421 & $\begin{array}{l}\text { Similar to HLA-B-associated } \\
\text { transcript nuclease }\end{array}$ & & $\begin{array}{c}\mathrm{AD} \\
33 \mathrm{p}: 30 \mathrm{c}\end{array}$ & plant \\
\hline gi|38174030 & $\begin{array}{l}\text { HLA-B associated transcript } 1 \text { : } \\
\text { RNA transport spliceosome } \\
\text { (Xenopus tropicalis) }\end{array}$ & & & plant \\
\hline gi| 17862978 & $\begin{array}{l}\text { SDO7045p (D. melanogaster }) \\
\text { IGF-II mRNA binding protein }\end{array}$ & & & plant \\
\hline gi| 157019434 & $\begin{array}{l}\text { AGA P010876-PA (A. gambia) } \\
\text { RNA degradation }\end{array}$ & $\begin{array}{c}\mathrm{AD} \\
22 \mathrm{p}: 20 \mathrm{c}\end{array}$ & $\begin{array}{c}\text { AD } \\
33 p: 30 c\end{array}$ & plant \\
\hline \multicolumn{5}{|c|}{ Protein synthesis } \\
\hline gi 15081324 & $\begin{array}{l}\text { Ribosomal protein } \mathrm{L} 18 \\
\text { (Spodoptera frugiperda) }\end{array}$ & $\begin{array}{c}\mathrm{AD} \\
22 \mathrm{p}: 20 \mathrm{c}\end{array}$ & $\begin{array}{c}\mathrm{AD} \\
33 \mathrm{p}: 30 \mathrm{c}\end{array}$ & plant \\
\hline gi $\mid 15213760$ & $\begin{array}{l}\text { Ribosomal protein L13 }(S . \\
\text { frugiperda) }\end{array}$ & $\begin{array}{c}\mathrm{AD} \\
22 \mathrm{p}: 20 \mathrm{c}\end{array}$ & $\begin{array}{c}\text { AD } \\
33 \mathrm{p}: 30 \mathrm{c}\end{array}$ & plant \\
\hline gi| 15213806 & Ribosomal protein S7 & $\begin{array}{c}\text { AD } \\
22 \mathrm{p}: 20 \mathrm{c}\end{array}$ & $\begin{array}{c}\text { AD } \\
33 \mathrm{p}: 30 \mathrm{c}\end{array}$ & plant \\
\hline gi $\mid 15213808$ & $\begin{array}{l}\text { Ribosomal protein } \mathrm{S} 10 \\
\text { (S.frugiperda) }\end{array}$ & $\begin{array}{c}\mathrm{AD} \\
22 \mathrm{p}: 20 \mathrm{c}\end{array}$ & $\begin{array}{c}\mathrm{AD} \\
33 \mathrm{p}: 30 \mathrm{c}\end{array}$ & plant \\
\hline gi|16566722 & $\begin{array}{l}\text { Ribosomal protein } \mathrm{S} 3 \mathrm{~A}(S . \\
\text { frugiperda) }\end{array}$ & $\begin{array}{c}\mathrm{AD} \\
22 \mathrm{p}: 20 \mathrm{c}\end{array}$ & $\begin{array}{c}\text { AD } \\
33 \mathrm{p}: 30 \mathrm{c}\end{array}$ & plant \\
\hline gi|16566725 & $\begin{array}{l}\text { Ribosomal protein } \mathrm{S} 4(S . \\
\text { frugiperda) }\end{array}$ & $\begin{array}{c}\mathrm{AD} \\
22 \mathrm{p}: 20 \mathrm{c}\end{array}$ & $\begin{array}{c}\mathrm{AD} \\
33 \mathrm{p}: 30 \mathrm{c}\end{array}$ & plant \\
\hline gi|16566731 & $\begin{array}{l}\text { Ribosomal protein } \mathrm{S} 6(S . \\
\text { frugiperda) }\end{array}$ & $\begin{array}{c}\mathrm{AD} \\
22 \mathrm{p}: 20 \mathrm{c}\end{array}$ & $\begin{array}{c}\mathrm{AD} \\
33 \mathrm{p}: 30 \mathrm{c}\end{array}$ & plant \\
\hline gi|16566734 & $\begin{array}{l}\text { Ribosomal protein } \mathrm{S} 16(S . \\
\text { frugiperda) }\end{array}$ & $\begin{array}{c}\mathrm{AD} \\
22 \mathrm{p}: 20 \mathrm{c}\end{array}$ & $\begin{array}{c}\mathrm{AD} \\
33 \mathrm{p}: 30 \mathrm{c}\end{array}$ & plant \\
\hline gi|18253041 & $\begin{array}{l}\text { 60S acidic ribosomal protein } \mathrm{PO} \\
(\text { S. frugiperda) }\end{array}$ & $\begin{array}{c}\mathrm{AD} \\
22 \mathrm{p}: 20 \mathrm{c}\end{array}$ & $\begin{array}{c}\text { AD } \\
33 \mathrm{p}: 30 \mathrm{c}\end{array}$ & plant \\
\hline gi|18253049 & $\begin{array}{l}\text { Ribosomal protein L7 }(S . \\
\text { frugiperda) }\end{array}$ & $\begin{array}{c}\mathrm{AD} \\
22 \mathrm{p}: 20 \mathrm{c}\end{array}$ & $\begin{array}{c}\mathrm{AD} \\
33 \mathrm{p}: 30 \mathrm{c}\end{array}$ & plant \\
\hline gi|27260896 & $\begin{array}{l}\text { Ribosomal protein } \mathrm{S} 2(S . \\
\text { frugiperda) }\end{array}$ & $\begin{array}{c}\mathrm{AD} \\
22 \mathrm{p}: 20 \mathrm{c}\end{array}$ & $\begin{array}{c}\text { AD } \\
33 \mathrm{p}: 30 \mathrm{c}\end{array}$ & plant \\
\hline gi|27462516 & $\begin{array}{l}60 \mathrm{~S} \text { ribosomal protein } \mathrm{L} 15(\mathrm{~S} \text {. } \\
\text { frugiperda) }\end{array}$ & $\begin{array}{c}\text { AD } \\
22 \mathrm{p}: 20 \mathrm{c}\end{array}$ & $\begin{array}{c}\text { AD } \\
33 p: 30 c\end{array}$ & plant \\
\hline gi|3282245 & Ribosomal protein L5 (B. mori) & $\begin{array}{c}\mathrm{AD} \\
22 \mathrm{p}: 20 \mathrm{c}\end{array}$ & $\begin{array}{c}\mathrm{AD} \\
33 \mathrm{p}: 30 \mathrm{c}\end{array}$ & plant \\
\hline gi| 62083433 & Ribosomal protein PO & $\begin{array}{c}\text { AD } \\
22 \mathrm{p}: 20 \mathrm{c}\end{array}$ & $\begin{array}{c}\text { AD } \\
33 p: 30 c\end{array}$ & plant \\
\hline gi|18253045 & $\begin{array}{l}\text { 60S acidic ribosomal protein } \mathrm{P} 2 \\
\text { (S. frugiperda) }\end{array}$ & $\begin{array}{c}\mathrm{AD} \\
22 \mathrm{p}: 20 \mathrm{c}\end{array}$ & $\begin{array}{c}\mathrm{AD} \\
33 \mathrm{p}: 30 \mathrm{c}\end{array}$ & \\
\hline
\end{tabular}




\section{Table 1 (continued)}

\begin{tabular}{|c|c|c|c|c|}
\hline gi| 18253047 & $\begin{array}{l}\text { Ribosomal protein L3 }(S . \\
\text { frugiperda) }\end{array}$ & $\begin{array}{c}\text { AD } \\
22 \mathrm{p}: 20 \mathrm{c}\end{array}$ & & plant \\
\hline gi| 18253051 & $\begin{array}{l}\text { Ribosomal protein L18A }(S . \\
\text { frugiperda) }\end{array}$ & $\begin{array}{c}\text { AD } \\
22 \mathrm{p}: 20 \mathrm{c}\end{array}$ & & plant \\
\hline gi 18253055 & $\begin{array}{l}\text { Ribosomal protein } \mathrm{S} 8(S . \\
\text { frugiperda) }\end{array}$ & $\begin{array}{c}\mathrm{AD} \\
22 \mathrm{p}: 20 \mathrm{c}\end{array}$ & & plant \\
\hline gi| 15213762 & $\begin{array}{l}\text { Ribosomal protein L13A }(S . \\
\text { frugiperda) }\end{array}$ & $\begin{array}{c}\mathrm{AD} \\
22 \mathrm{p}: 20 \mathrm{c}\end{array}$ & & \\
\hline gi $\mid 15213764$ & $\begin{array}{l}\text { Ribosomal protein L14 }(S . \\
\text { frugiperda) }\end{array}$ & $\begin{array}{c}\mathrm{AD} \\
22 \mathrm{p}: 20 \mathrm{c}\end{array}$ & & \\
\hline gi| 15213780 & $\begin{array}{l}\text { Ribosomal protein L30 }(S \text {. } \\
\text { frugiperda) }\end{array}$ & $\begin{array}{c}\mathrm{AD} \\
22 \mathrm{p}: 20 \mathrm{c}\end{array}$ & & \\
\hline gi| 15213814 & $\begin{array}{l}\text { Ribosomal protein } \mathrm{S} 13(S . \\
\text { frugiperda) }\end{array}$ & $\begin{array}{c}\mathrm{AD} \\
22 \mathrm{p}: 20 \mathrm{c}\end{array}$ & & \\
\hline gi| 15213824 & $\begin{array}{l}\text { Ribosomal protein } \mathrm{S} 18(S . \\
\text { frugiperda) }\end{array}$ & $\begin{array}{c}\mathrm{AD} \\
22 \mathrm{p}: 20 \mathrm{c}\end{array}$ & & \\
\hline gi $\mid 15213826$ & $\begin{array}{l}\text { Ribosomal protein } \mathrm{S} 19(S . \\
\text { frugiperda) }\end{array}$ & $\begin{array}{c}\mathrm{AD} \\
22 \mathrm{p}: 20 \mathrm{c}\end{array}$ & & \\
\hline gi|49532832 & $\begin{array}{l}\text { Ribosomal protein L8 (Plutella } \\
\text { xylostella) }\end{array}$ & $\begin{array}{c}\mathrm{AD} \\
22 \mathrm{p}: 20 \mathrm{c}\end{array}$ & & plant \\
\hline gi|54609281 & Ribosomal protein 5A (B. mori) & $\begin{array}{c}\text { AD } \\
22 p: 20 c\end{array}$ & & plant \\
\hline gi|54609203 & Ribosomal protein L7A (B. mori) & & & plant \\
\hline gi|54609243 & Ribosomal protein L16 (B. mori) & & & plant \\
\hline gi 54609285 & Ribosomal protein S3 (B. mori) & & & plant \\
\hline gi| 14994664 & $\begin{array}{l}\text { Ribosomal protein L9 }(S . \\
\text { frugiperda) }\end{array}$ & $\begin{array}{c}\mathrm{AD} \\
22 \mathrm{p}: 20 \mathrm{c}\end{array}$ & & plant \\
\hline gi|54609225 & Ribosomal protein L17 (B. mori) & $\begin{array}{c}\mathrm{AD} \\
22 \mathrm{p}: 20 \mathrm{c}\end{array}$ & & \\
\hline gi|56462224 & $\begin{array}{l}\text { Ribosomal protein } 23 \text { (Lonomia } \\
\text { obliqua) }\end{array}$ & $\begin{array}{c}\mathrm{AD} \\
22 \mathrm{p}: 20 \mathrm{c}\end{array}$ & & \\
\hline gi|66525285 & $\begin{array}{l}\text { 60S ribosomal protein L4 isoform } \\
1 \text { (A. melifora) }\end{array}$ & $\begin{array}{c}\mathrm{AD} \\
22 \mathrm{p}: 20 \mathrm{c}\end{array}$ & & \\
\hline gi| 6469517 & $\begin{array}{l}\text { Translation initiation factor } 5 \mathrm{~A}(S \text {. } \\
\text { frugiperda) }\end{array}$ & $\begin{array}{c}\mathrm{AD} \\
22 \mathrm{p}: 20 \mathrm{c}\end{array}$ & $\begin{array}{c}\mathrm{AD} \\
33 \mathrm{p}: 30 \mathrm{c}\end{array}$ & \\
\hline gi| 51965706 & $\begin{array}{l}\text { Translation initiation factor } 2 \mathrm{~g} \\
\text { subunit }\end{array}$ & $\begin{array}{c}\mathrm{AD} \\
22 \mathrm{p}: 20 \mathrm{c}\end{array}$ & & plant \\
\hline gi|28627569 & $\begin{array}{l}\text { Translation elongation factor } 2(S \text {. } \\
\text { exigua) }\end{array}$ & $\begin{array}{c}\text { AD } \\
22 \mathrm{p}: 20 \mathrm{c}\end{array}$ & $\begin{array}{c}\text { AD } \\
33 p: 30 c\end{array}$ & plant \\
\hline gi|78190623 & $\begin{array}{l}\text { EF2; eukaryotic translation } \\
\text { initiation factor } 2 \text { (Suberites } \\
\text { fuscus) }\end{array}$ & $\begin{array}{c}\mathrm{AD} \\
22 \mathrm{p}: 20 \mathrm{c}\end{array}$ & $\begin{array}{c}\mathrm{AD} \\
33 \mathrm{p}: 30 \mathrm{c}\end{array}$ & plant \\
\hline gi|27462592 & eIF2a subunit ( $S$. frugiperda) & $\begin{array}{c}\mathrm{AD} \\
22 \mathrm{p}: 20 \mathrm{c}\end{array}$ & $\begin{array}{c}\text { AD } \\
33 p: 30 c\end{array}$ & \\
\hline gi| 17862358 & $\begin{array}{l}\text { eRF/ARF - translation factor ( } D . \\
\text { melanogaster) LD23157p }\end{array}$ & $\begin{array}{c}\mathrm{AD} \\
22 \mathrm{p}: 20 \mathrm{c}\end{array}$ & $\begin{array}{c}\text { AD } \\
33 \mathrm{p}: 30 \mathrm{c}\end{array}$ & plant \\
\hline gi| 12328431 & Elongation Factor 1a (B. mori) & $\begin{array}{c}\mathrm{AD} \\
22 \mathrm{p}: 20 \mathrm{c}\end{array}$ & $\begin{array}{c}\text { AD } \\
33 \mathrm{p}: 30 \mathrm{c}\end{array}$ & plant \\
\hline gi|28822215 & Elongation Factor 1a & $\begin{array}{c}\text { AD } \\
22 \mathrm{p}: 20 \mathrm{c}\end{array}$ & $\begin{array}{c}\text { AD } \\
33 \mathrm{p}: 30 \mathrm{c}\end{array}$ & plant \\
\hline gi| 87248115 & Elongation factor 1a (B. mori) & $\begin{array}{c}\mathrm{AD} \\
22 \mathrm{p}: 20 \mathrm{c}\end{array}$ & $\begin{array}{c}\text { AD } \\
33 p: 30 \mathrm{C}\end{array}$ & plant \\
\hline gi|232030 & Elongation factor $1 \mathrm{~b}$ & $\begin{array}{c}\mathrm{AD} \\
22 \mathrm{p}: 20 \mathrm{c}\end{array}$ & $\begin{array}{c}\text { AD } \\
33 \mathrm{p}: 30 \mathrm{c}\end{array}$ & \\
\hline gi| 56123349 & Elongation Factor & $\begin{array}{c}\text { AD } \\
22 \mathrm{p}: 20 \mathrm{c}\end{array}$ & $\begin{array}{c}\text { AD } \\
33 \mathrm{p}: 30 \mathrm{c}\end{array}$ & plant \\
\hline gi 135089 & Alanyl t-RNA synthetase & $\begin{array}{c}\mathrm{AD} \\
22 \mathrm{p}: 20 \mathrm{c}\end{array}$ & $\begin{array}{c}\mathrm{AD} \\
33 \mathrm{p}: 30 \mathrm{c}\end{array}$ & plant \\
\hline gi| 1351153 & Glycyl-tRNA synthetase & $\begin{array}{c}\mathrm{AD} \\
22 \mathrm{p}: 20 \mathrm{c}\end{array}$ & $\begin{array}{c}\mathrm{AD} \\
33 \mathrm{p}: 30 \mathrm{c}\end{array}$ & plant \\
\hline gi|328787158 & $\begin{array}{l}\text { Valyl-tRNA synthetase isoform } 1 \\
\text { (A. mellifera) }\end{array}$ & & $\begin{array}{c}\text { AD } \\
33 p: 30 c\end{array}$ & \\
\hline \multicolumn{5}{|l|}{ Metabolism } \\
\hline gi|28971712 & $\begin{array}{l}\text { Mitochondrial aconitase A swivel } \\
\text { domain. } \\
\text { (Antheraea yamamai) }\end{array}$ & $\begin{array}{c}\mathrm{AD} \\
22 \mathrm{p}: 20 \mathrm{c}\end{array}$ & $\begin{array}{c}\mathrm{AD} \\
33 \mathrm{p}: 30 \mathrm{c}\end{array}$ & plant \\
\hline
\end{tabular}


Table 1 (continued)

\begin{tabular}{|c|c|c|c|c|}
\hline gi 66508366 & $\begin{array}{l}\text { Inosine-5'-monophosphate } \\
\text { dehydrogenase isoform } 1 \text { ( } A \text {. } \\
\text { mellifora) }\end{array}$ & & $\begin{array}{c}\mathrm{AD} \\
33 \mathrm{p}: 30 \mathrm{c}\end{array}$ & \\
\hline gi|87248239 & Transketolase (B. mori) & $\begin{array}{c}\text { AD } \\
22 \mathrm{p}: 20 \mathrm{c}\end{array}$ & $\begin{array}{c}\text { AD } \\
33 \mathrm{p}: 30 \mathrm{c}\end{array}$ & plant \\
\hline gi| 66523390 & $\begin{array}{l}\text { Glutamate dehydrogenase, } \\
\text { mitochondrial isoform I }(A \text {. } \\
\text { mellifera })\end{array}$ & $\begin{array}{c}\mathrm{AD} \\
22 \mathrm{p}: 20 \mathrm{c}\end{array}$ & $\begin{array}{c}\mathrm{AD} \\
33 \mathrm{p}: 30 \mathrm{c}\end{array}$ & plant \\
\hline gi 38371675 & $\begin{array}{l}\text { Pyruvate kinase (B. mori) } \\
\text { glycolysis }\end{array}$ & $\begin{array}{c}\mathrm{AD} \\
22 \mathrm{p}: 20 \mathrm{c}\end{array}$ & $\begin{array}{c}\mathrm{AD} \\
33 \mathrm{p}: 30 \mathrm{c}\end{array}$ & \\
\hline gi|53830714 & Enolase (Oncometopia nigricans) & $\begin{array}{c}\mathrm{AD} \\
22 \mathrm{p}: 20 \mathrm{c}\end{array}$ & $\begin{array}{c}\mathrm{AD} \\
33 \mathrm{p}: 30 \mathrm{c}\end{array}$ & \\
\hline gi| 157013238 & AGA PO12048-PA (A. gambia) & $\begin{array}{c}\mathrm{AD} \\
22 \mathrm{p}: 20 \mathrm{c}\end{array}$ & $\begin{array}{c}\mathrm{AD} \\
33 \mathrm{p}: 30 \mathrm{c}\end{array}$ & \\
\hline gi|45330818 & $\begin{array}{l}\text { Fructose 1,6-bisphosphate aldolase } \\
\text { (Antheraea yanamai) }\end{array}$ & & $\begin{array}{c}\text { AD } \\
33 \mathrm{p}: 30 \mathrm{c}\end{array}$ & \\
\hline gi|20151455 & $\begin{array}{l}\text { GH26789p (D. melanogaster }) \\
\text { Glutamate synthase }\end{array}$ & & & plant \\
\hline gi|34305305 & $\begin{array}{l}\text { 5-Aminoimidazole-4-carboxamide } \\
\text { ribonucleotide formyl } \\
\text { tranferase/IMP cyclohydrolase } \\
\text { (Leptinotarsa decemlineata) }\end{array}$ & & $\begin{array}{c}\mathrm{AD} \\
33 \mathrm{p}: 30 \mathrm{c}\end{array}$ & plant \\
\hline gi|333468507 & $\begin{array}{l}\text { AGAP003168-PA (A. gambia) } \\
\text { isocitrate/isopropyl malate } \\
\text { dehydrogenase }\end{array}$ & & $\begin{array}{c}\mathrm{AD} \\
33 \mathrm{p}: 30 \mathrm{c}\end{array}$ & plant \\
\hline gi| 85062656 & Asparagine synthetase (B. mori) & & $\begin{array}{c}\mathrm{AD} \\
33 \mathrm{p}: 30 \mathrm{c}\end{array}$ & plant \\
\hline gi| $\mid 87248157$ & $\begin{array}{l}\text { Hydroxyacyl-coenzyme A } \\
\text { dehydrogenase (B. mori) }\end{array}$ & & & plant \\
\hline $\operatorname{gi} \mid 51555846$ & $\begin{array}{l}\text { Glycerol-3-phosphate } \\
\text { dehydrogenase-1 (B. mori) }\end{array}$ & $\begin{array}{c}\mathrm{AD} \\
22 \mathrm{p}: 20 \mathrm{c}\end{array}$ & $\begin{array}{c}\mathrm{AD} \\
33 \mathrm{p}: 30 \mathrm{c}\end{array}$ & \\
\hline gi|328777933 & $\begin{array}{l}\text { Nucleoside diphosphate kinase ( } A \text {. } \\
\text { mellifera) }\end{array}$ & $\begin{array}{c}\mathrm{AD} \\
22 \mathrm{p}: 20 \mathrm{c}\end{array}$ & $\begin{array}{c}\text { AD } \\
33 \mathrm{p}: 30 \mathrm{c}\end{array}$ & \\
\hline gi 82754585 & $\begin{array}{l}\text { Glyceraldehyde 3-phosphate } \\
\text { dehydrogenase (Colias eurytheme) }\end{array}$ & $\begin{array}{c}\mathrm{AD} \\
22 \mathrm{p}: 20 \mathrm{c}\end{array}$ & $\begin{array}{c}\mathrm{AD} \\
33 \mathrm{p}: 30 \mathrm{c}\end{array}$ & \\
\hline gi 157012452 & $\begin{array}{l}\text { AGAP001957-PA (A. gambia) } \\
\text { lipid-binding site }\end{array}$ & $\begin{array}{c}\mathrm{AD} \\
22 \mathrm{p}: 20 \mathrm{c}\end{array}$ & $\begin{array}{c}\mathrm{AD} \\
33 \mathrm{p}: 30 \mathrm{c}\end{array}$ & \\
\hline gi|28261391 & $\begin{array}{l}\text { ADP/ATP translocase } \\
\text { (mitochondria) (B. mori) }\end{array}$ & $\begin{array}{c}\mathrm{AD} \\
22 \mathrm{p}: 20 \mathrm{c}\end{array}$ & $\begin{array}{c}\mathrm{AD} \\
33 \mathrm{p}: 30 \mathrm{c}\end{array}$ & plant \\
\hline \multicolumn{5}{|l|}{ Keratin } \\
\hline gi 119395750 & Keratin, type II cytoskeletal I & $\begin{array}{c}\mathrm{AD} \\
22 \mathrm{p}: 20 \mathrm{c}\end{array}$ & $\begin{array}{c}\mathrm{AD} \\
33 \mathrm{p}: 30 \mathrm{c}\end{array}$ & plant \\
\hline gi| 181402 & Epidermal cytokeratin 2 & $\begin{array}{c}\mathrm{AD} \\
22 \mathrm{p}: 20 \mathrm{c}\end{array}$ & $\begin{array}{c}\text { AD } \\
33 \mathrm{p}: 30 \mathrm{c}\end{array}$ & plant \\
\hline gi 2443314 & Keratin 14 & $\begin{array}{c}\mathrm{AD} \\
22 \mathrm{p}: 20 \mathrm{c}\end{array}$ & $\begin{array}{c}\mathrm{AD} \\
33 \mathrm{p}: 30 \mathrm{c}\end{array}$ & plant \\
\hline gi 435476 & Cytokeratin & $\begin{array}{c}\mathrm{AD} \\
22 \mathrm{p}: 20 \mathrm{c}\end{array}$ & $\begin{array}{c}\mathrm{AD} \\
33 \mathrm{p}: 30 \mathrm{c}\end{array}$ & plant \\
\hline gi| 46399073 & Type II $\alpha$-keratin & & $\begin{array}{c}\mathrm{AD} \\
33 \mathrm{p}: 30 \mathrm{c}\end{array}$ & plant \\
\hline
\end{tabular}

\section{Results}

\subsection{Proteomics}

A conservative approach was taken to identify diet-dependent protein expression. Proteins were identified based on the presence of at least two peptides and a protein must be present in all of the independent biological replicates to be considered valid. Using this criteria, 131 soluble proteins were identified in labial salivary gland homogenates and the diet-specific expression characterized (Fig. 1, Table 1). This is a rigorous approach as one of the caveats to nanoLC/ESI/MS/MS is that most abundant peptides are detected and this could, in rare cases, lead to masking of proteins. Therefore, Supplemental Table 2 depicts the expressed proteins if a less strin- gent approach was used; proteins identified here are based on the presence of two or more peptides but the protein may be present in only two of the three biological replications. Proteins were categorized into the Gene Ontology functional and biological processes (Figs. 2 and 3). Using this approach, for a single protein multiple categories may be identified. Over $10 \%$ of the biological process classifications in the labial salivary glands are associated with protein secretion.

\subsection{Proteins associated with protein secretion processes}

Ribosomes association with the Sec61 translocon pore allows the growing polypeptide chain to enter the ER lumen during translation; this heteromeric, membrane-spanning protein complex is 
comprised of Sec61 $\alpha, \beta$ and $\gamma$ (Greensfield and High, 1999). The Sec61 $\alpha$-subunit was identified in $S$. exigua labial salivary glands (Table 1). Calnexin and $\mathrm{Ca}^{2}$-dependent calreticulin recognize and bind to the GlcMan9GlcAc2 of newly synthesized glycoproteins (Michalak et al., 2009); calreticulin stabilizes the nascent polypeptide and acts as a docking protein for other enzymes, such as the protein disulfide isomerase (PDI) ERp57 (Baksh et al., 1995; Frickel et al., 2004; Pollock et al., 2004; Hosoda et al., 2010). Calreticulin has been identified in salivary secretions of numerous tick species including Amblyomma americanum, Dermacentor variabilis, Haemaphysalis longicornis, Ixodes scapularis and Rhipicephalis sanguineus (Jaworski et al., 1995; Ferreira et al., 2002; Nene et al., 2002; Xu et al., 2004, 2005). Calreticulin is also identified in the labial salivary glands of caterpillars which fed on plants or the 33p:30c artificial diet (Table 1) ER-associated PDIs act as chaperones by catalyzing the oxidation and isomerization of nascent polypeptides, stabilizing the protein structure and overexpression of PDI often results in increased heterologous protein secretion (Davis et al., 2000; Ellgaard and Helenius, 2003; Chung et al., 2004; Inan et al., 2006; Zhang et al., 2006; Mohan et al., 2007; Goo et al., 2008). PDIs have been identified in tick salivary glands and secretions (Knizetova et al., 2006; Liao et al., 2007). In fact, in response to blood feeding, Pdi gene expression increased in the tick $\mathrm{H}$. longicornis (Liao et al., 2007). Protein levels also increased in Helicoverpa armigera midgut cells which had been chemically treated to induce apoptosis (Courtiade et al., 2011). Recently, de la Paz Celorio-Mancera et al. (2012) reported PDIs in both the labial and mandibular salivary glands of $V$. gonerilla caterpillars. Two protein disulfide isomerases, including ERp57, are identified in S. exigua caterpillar labial salivary glands (Table 1 ).

Peptidyl-propyl cis-trans isomerase (PPI) catalyzes a key ratelimiting step in protein folding, the conversion of the peptide bond of proline from the cis to trans isomer (Kay, 1996). As well, these

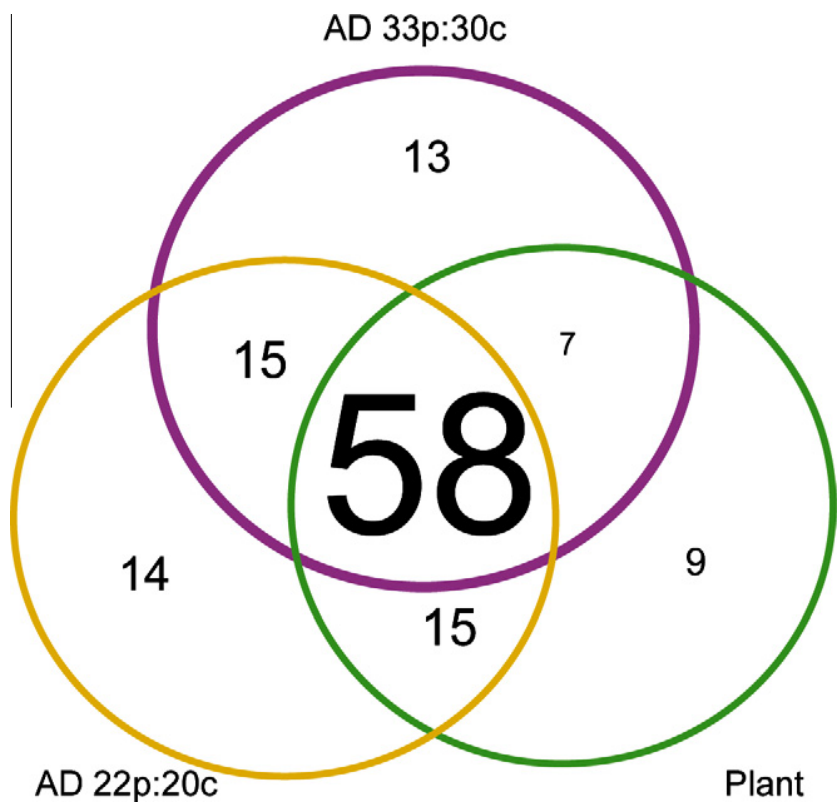

Fig. 1. Venn diagram depicting soluble proteins identified in the labial salivary glands of S. exigua caterpillars fed different diets: An artificial diet containing $22 \%$ protein and 20\% digestible carbohydrate (AD 22p:20c), artificial diet containing 33\% protein and $30 \%$ digestible carbohydrate (AD 33p:30c) or the plant M. truncatula. Numbers in the circles represent number of soluble proteins identified in triplicate experiments and the font size reflects these protein numbers. Numbers in overlapping circles indicate shared proteins; 58 proteins are found in caterpillar labial salivary glands independent of diet. Total proteins identified in labial salivary glands of caterpillars fed AD 22p:20c, AD 33p:30c and plant are 102, 93 and 89, respectively (see Table 1 ). proteins often act as cochaperones to Heat Shock Protein 90s (HSP90s) (Owens-Grillo et al., 1996). This protein was only identified in labial salivary glands of $S$. exigua caterpillars that fed on a plant diet (Table 1 ) and was also identified in $H$. zea salivary secretions (de la Paz Celorio-Mancera et al., 2011).

Cargo proteins destined for secretion then undergo anterograde transport to the Golgi apparatus for further sorting and processing. Sec23 forms an integral part of the Coat Protein Complex II (COP II) which is involved in the anterograde transport of secretory vesicles from the ER to the Golgi apparatus (Fromme et al., 2008). Specifically, Sec23 is involved in tethering and transporting the vesicle along microtubules to the Golgi. This protein was identified in caterpillars fed on the protein-poor diets; plant and 22p:20c (Table 1).

In vesicular trafficking, Rab GTPases are master regulators primarily involved in docking and vesicle fusion as well as protein quality control (Jordens et al., 2005; Grosshans et al., 2006; Schwartz et al., 2007; Fukuda, 2008; Stenmark, 2009; Diekmann et al., 2011; Lee et al., 2011). Specific Rab GTPases are associated with explicit transport vesicles and/or stages (Stein et al., 2003). For example, Rab7, a small GTPase identified in this proteomic analysis, is associated with retrograde trafficking between the early and late endosomal vesicles and, also, between late endosomal and lysosome fusion (Schwartz et al., 2007). Rab7 was only identified only in the labial salivary glands of caterpillars fed on the carbohydrate- and protein-rich diet, 33p:30c (Table 1).

These small RAB GTPases are negatively regulated through their association with guanine nucleotide dissociation inhibitors (GDIs) (Gilbert and Burd, 2001; Goody et al., 2005). After vesicle fusion, inactive GDP-bound Rab GTPases associate with GDP dissociation inhibitor (GDI) proteins that remove Rab proteins to recycle them back to donor membranes (Stein et al., 2003). Therefore, GDIs are involved in the regulation of GTPase activity and localization by delivery of Rab GTPases to the correct membrane compartments (Gilbert and Burd, 2001; Goody et al., 2005). The yeast gdi1 mutant leads to the loss of protein transport and Drosophila gdi mutants are lethal presumably affecting secretion processes associate with development (Garrett et al., 1994; Ricard et al., 2001). A GDI protein was found in the labial salivary glands of all caterpillars. Caterpillar labial salivary glands contain a member of the ezrin/ radixin/moesin protein family which may act to disrupt this GDIGTPase association (Table 1) (Takahashi et al., 1997). Of interest, HSP90 chaperones may also be involved in the interaction between GDI1 and target Rab GTPases (Raffaniello et al., 2009). In the exocrinic rat derived pancreatic cell line AR42J, HSP 90 co-localizes with Rab-GDI to stimulate vesicular secretion.

In caterpillar labial salivary glands, the intracellular receptor RACK-1 was identified in caterpillars reared on all diets (Table 1). When Rack-1 binds to activated protein kinase C (PKC), the receptor localizes to the appropriate membrane, stabilizing PKC and acting as a scaffold protein to facilitate interactions between PKC and downstream targets (Brandon et al., 2002; McCahill et al., 2002). In mammalian systems, PKC phosphorylation of target proteins such as $25 \mathrm{kDa}$ synaptosome-associated protein (SNAP-25) and Munc18 leads to the activation of different exocytosis stages (Morgan et al., 2005). A putative link between RACK-1 and glyceraldehyde-3phosphate dehydrogenase (GA3PDH) has been identified in the transcystosis of viral particles in aphid saliva (Seddas et al., 2004). Beet Western Yellows Virus particles must traverse aphid salivary gland epithelial membranes. In this case, transcytosis is believed to be mediated by interactions between viral particles and the host aphid proteins Rack-1 and GA3PDH. In eukaryotic glycolysis, GA3PDH catalyses the reversible conversion of glyceraldehyde-3-phosphate to 1,3-diphosphoglycerate generating $\mathrm{NAD}(\mathrm{P}) \mathrm{H}$. However, when phosphorylated by PKC, this protein promotes microtubule formation and anchoring to vesicular tubular clusters that are necessary for the anterograde movement of coat protein 
A. Plant

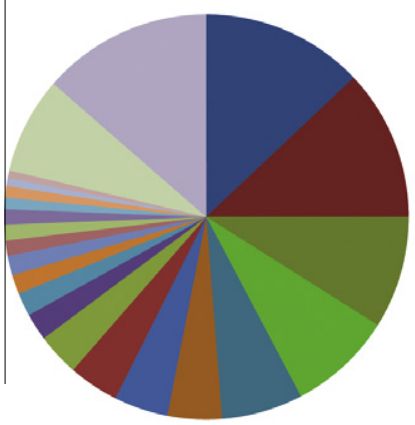

Ntd binding

Structural

NA binding

Hydrolase

lon binding

Transporter
B. $A D 22 p: 20 c$

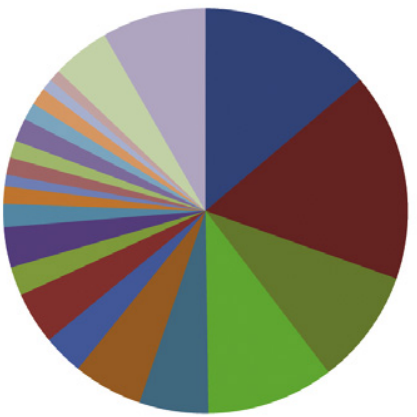

Protein-protein

Oxidoreductase

Catalytic

Electron carrier

Transferase

Lyase
C. $A D 33 p: 30 c$

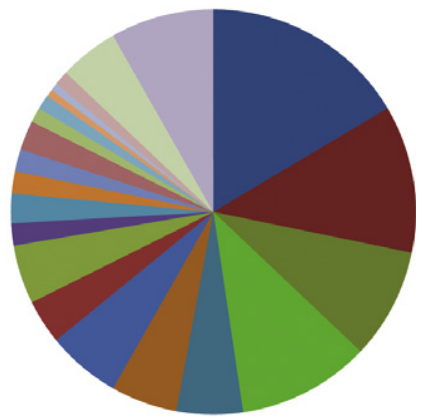

Regulator

Molecular function

Misc

Unclassified

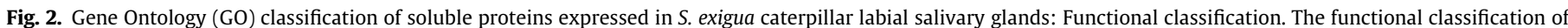

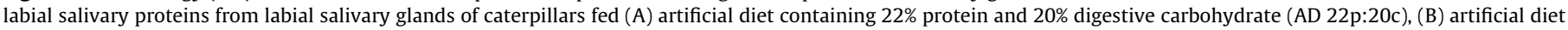

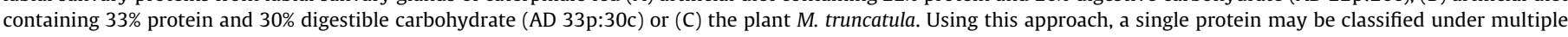
categories. For simplicity, some categories were combined.

A. Plant

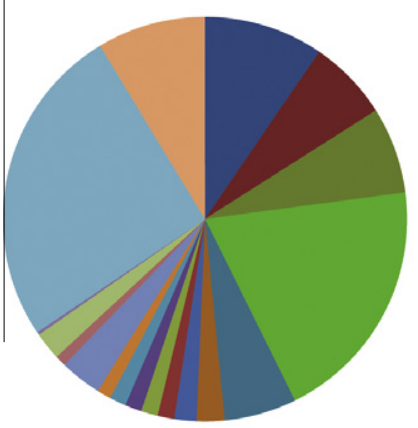

Translation

Energy metabolism

Transport (ion, hydrogen)

Metabolism

Signal transduction \& regulation

Oxidoreduction
B. AD 22p:20c

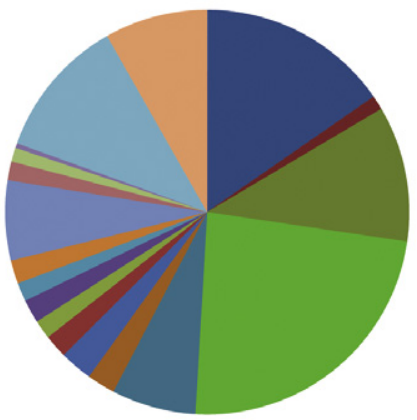

Cellular respiration

Development

Multicellular processes

Catabolism

Cytoskeleton

Electron transport chain
C. $\mathrm{AD} 33 \mathrm{p}: 30 \mathrm{c}$

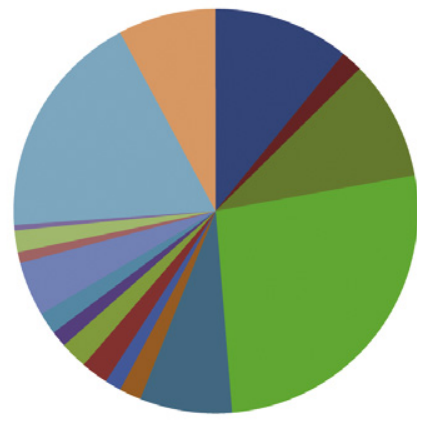

Protein folding, modification \& transport

Protein degradation

Vesicle transport \& secretion

Digestion

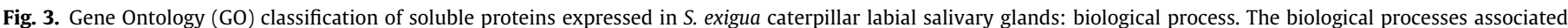

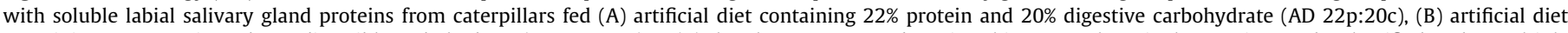

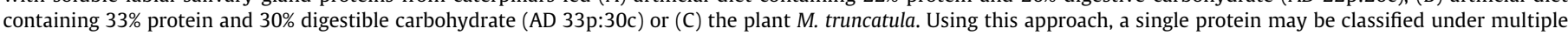
categories. For simplicity, some categories were combined.

complex I (COPI) vesicles (Csukai and Mochly-Rosen, 1999; Tisdale et al., 2009). Therefore, given these diverse biological roles, GA3PDH provides a potential link between glycolysis and cellular carbohydrate status with vesicular exocytosis (Glaser et al., 2002). GA3PDH was identified in the labial salivary glands of caterpillars fed artificial diets, both 22:20 and 33:30, but not on plant diet (Table 1 ). As well, this protein was identified in the salivary secretions of $H$. zea caterpillars reared on artificial diet (de la Paz Celorio-Mancera et al., 2011). RACK1 has also been implicated in targeting proteins for proteasome-mediated degradation (Ruan et al., 2009); this activity is regulated by the protein phosphatase calcineurin through the dephosphorylation of RACK1 (Liu et al., 2007).

\subsection{Heat shock proteins}

Heat shock proteins (HSPs) function in the cell as molecular chaperones that bind to nascent polypeptide chains and function 
as holdases or foldases to ensure proper protein folding (Braakman and Bulleid, 2011). Initially identified and characterized based on their induction in response to heat stress, it is now recognized that HSPs may be constitutive and/or induced by a multitude of cellular stresses (Gupta and Tuteja, 2011). For example, HSP90 is constitutively expressed, comprising a major soluble ER protein, and only weakly induced by stress compared to HSP70 which has low endogenous levels but is a marker of ER-stress (Buchner, 1999; Landais et al., 2001). In response to stress, HSPs are crucial in protein refolding and preventing denaturation (Feder and Hofmann, 1999; Eletto et al., 2010).

Based on their molecular weight, HSPs are categorized into 5 major classes, small HSP ( $<30 \mathrm{kD}$ ), 60, 70, 90 and 100 (Sakano et al., 2006). Classes 60, 70 and 90 were identified in the labial salivary glands of caterpillars fed on all diets; in contrast, the small HSP 21.4 was only identified in caterpillars fed on the proteinand carbohydrate-rich diet, 33p:30c (Table 1). In B. mori, expression of shsp21.4 was high in the silk glands of this caterpillar ( $\mathrm{Li}$ et al., 2009). In fat bodies, shsp21.4 levels are constitutive and downregulated after exposure to heat shock (Sakano et al., 2006).

Nutrient stress often results in the upregulation of HSPs, particularly glucose or amino acid deprivation (Lee, 2001; Abcouwer et al., 2002; Eletto et al., 2010). Grp79/BiP and Grp94/endoplasmin are constitutive but levels upregulated in response to nutrient stress (Heydari et al., 1993; Lee, 2001). BiP binds to nascent polypeptide chains and mediates ATP-dependent folding (Dudek et al., 2009); misfolded proteins bound to BiP for long periods are targeted for ERAD (Nishikawa et al., 2001; Ryoo and Steller, 2007; Bagola et al., 2011). Even though HSPs in the 70 and 90 class are constitutively expressed on all diets, Grp94/endoplasmin is present in the labial saliva of caterpillars fed on the artificial diet 22p:20c, suggesting nutrient stress on this diet (Table 1).

\subsection{Endoplasmic reticulum-associated protein degradation}

Misfolded proteins recognized by BiP, PDI and lectin sensors (EDEM1-3/Htmp/MnIIp/OS-9/Yos9P) are targeted for degradation through the ERAD system (Nishikawa et al., 2001; Ryoo and Steller, 2007; Mehnert et al., 2010; Bagola et al., 2011). Targeted proteins are uni- and di-ubiquitinated allowing their recognition by the Cdc48/p97 and ubiquitin fusion degradation 1/nuclear protein localization 4 complex (Ufd1/Npl4) complex which initiate their transport through Sec61 or derlin channels (Greensfield and High, 1999; Pye et al., 2007; Wolf and Stolz, 2012). After retrotranslocation from the ER, targeted proteins then assemble with E1-E3ubiquitin conjugating enzymes for further addition of ubiquitin and proteasome-mediated degradation (Herrmann et al., 2007). Ubiquitin was identified in the labial salivary glands of all caterpillars, irrespective of diet (Table 1); however, many of the components of the transport machinery and the regulatory 26S proteasome protein complex were only identified in the salivary glands of insects fed on the plant and 22p:20c diets, including Ufd1/Npl4, the ATP-dependent Tat-binding protein1 (TBP1/Rpt5), 26S proteasome subunit 4 protein (P26S4/Rpt2), RPN2 (Table 1). TBP1/Rpt5 and P26S4/Rpt2 represent two of the six 19S-associated $\mathrm{AAA}^{+}$ATPases that provide energy for protein unfolding and translocation into the $26 \mathrm{~S}$ proteasome through the 19S cap subcomplex. TBP1/Rpt5 has also been implicated in recruitment of targeted proteins through recognition of the polyubituitin tag and may be regulated through post-translational phosphorylation (Lam et al., 2002; Um et al., 2010). Both TBP1/Rpt5 and P26S4/Rpt2 are also implicated in the opening of the 20S proteasome subcomplex to allow entry of unfolded proteins (Smith et al., 2007; Park et al., 2010). Association between Rpn1 and Rpn2 forms a cone structure that links the 19S proteasome cap to the 20S proteolytic channel (Lander et al., 2012; Rosenzweig et al., 2012). As well, Rpn1 serves as a docking site for shuttle receptors that recognize ubiquitin-targeted proteins targeting them to the $26 \mathrm{~S}$ proteasome (Gomez et al., 2011). Therefore, proteins associated with the ERAD system were identified in the labial salivary glands of nutritionally-stressed caterpillars.

\subsection{Vacuolar type-ATPases}

Epithelial cells of insect salivary glands have abundant $\mathrm{H}^{+}$-ATPase (vacuolar ATP synthase (V-ATPase)) $/ \mathrm{nH}^{+}$cation $\left(\mathrm{K}^{+}\right.$or $\mathrm{Na}^{+}$) antiporter coupled systems that are involved in vesicular exocytosis and the ion and fluid reabsorption associated with salivary secretion (Nishi and Forgac, 2002; Wieczorek et al., 2009; Baumann and Walz, 2011). This highly conserved proton pump is comprised of two multimeric protein complexes, a membrane bound F0 complex and a F1 complex, which associate to form the active holoenzyme that hydrolyzes ATP to drive protons across a membrane generating a pH and chemiosmotic gradient (Sumner et al., 1995; Menzendorfer et al., 2000; Marshansky and Futai, 2008). A number of V-ATPase-dependent pathways are associated with vesicular trafficking (Marshansky and Futai, 2008). In mammals, isoform $\alpha 2$ is localized with the cis-Golgi or early endosomes; in these organelles, acidification of the lumen V-ATPase $\alpha 2$ results in $\mathrm{pH}$-dependent enzyme or channel activation and/or recruits proteins, such as ADP ribosylation factors and GTPases, required for vesicular trafficking to the organelle (Marshansky and Futai, 2008). Isoform $\alpha 1$ is associated with the Golgi body and involved in vesicle fusion and secretion, particularly in synaptic cells (Marshansky and Futai, 2008). Acidification of the lumen of dense-core secretory vesicles also activates enzymes needed for protein processing (Kim et al., 2006).

Homologous roles of V-ATPases in insect secretory cells are being investigated, particularly their role in salivary fluid secretion (Wieczorek et al., 2009; Baumann and Walz, 2011). In this proteomic study, V-ATPases subunits (H, C, B) were abundant in S. exigua labial salivary glands (Table 1 ). In addition, calcineurin, a $\mathrm{Ca}^{2+}$ dependent protein phosphatase, was identified in caterpillar labial salivary glands. Calcineurin is necessary for saliva production by blowfly salivary glands, but does not act directly on V-ATPase (Voss et al., 2010). Instead, calcineurin, activated through the $\mathrm{IP}_{3}$ pathway, modulates the cAMP pathway by sensitizing the cAMP-pathway associated serotonin receptor, by activating cAMP production by adenylate cyclase and by inhibiting cAMP degradation by phosphodiesterase, thereby, integrating the two signal transduction pathways activated by serotonin.

There also are close connections between V-ATPase activity and glucose/cellular energy levels. In the caterpillar midgut, a strong correlation between feeding and goblet cell plasma membrane V-ATPase activity is observed (Wieczorek et al., 2000). In midgut goblet cells and also in yeast, glucose deprivation results in the phosphorylation of the $\mathrm{F} 1$ subunit $\mathrm{C}$ by protein kinase $\mathrm{A}$, resulting in the reversible disassembly and inactivation of V-ATPase disassembly and inactivation (Sumner et al., 1995; Kane and Parra, 2000). In mammals, glucose regulation of the V-ATPase is further enhanced by the physical interaction and stabilization of the V0/ V1 haloenzyme by the glycolytic enzyme fructose 1,6-biosphosphate aldolase (Lu et al., 2007). In the experiment described herein, fructose 1,6-bisphosphate aldolase was only identified in labial salivary glands of caterpillars fed on the carbohydrate- and protein-rich diet, 33p:30c (Table 1).

\subsection{Non-classical protein secretion}

14-3-3 proteins are a ubiquitous family of small 28-33 kDa regulatory proteins involved in many cellular roles, including vesicle trafficking and exocytosis by the classical secretion pathway 
(Morrison, 1994; Chamberlain et al., 1995; Roth et al., 1999; Tzivion and Avruch, 2001). However, the $\varepsilon$-isoform of 14-3-3 proteins has also been implicated in a non-classical route of protein secretion that does not involve the ER-Golgi pathway (Carreño et al., 2005). In glioma cells, the $\varepsilon-14-3-3$ isoform interacts with phosphorylated endopeptidase 24.15 mediating extracellular secretion for neuropeptide degradation (Carreño et al., 2005). Two 14-3-3 isomers were detected in caterpillar labial salivary glands (Table 1 ); one isoform was detected only in caterpillars fed on the 22:20 artificial diet and the $\varepsilon$-isoform was identified in caterpillars fed the 22:20 and the 33:30 artificial diets, but not on the plant diet. Identification of the 14-3-3 $\varepsilon$-isoform suggests that this protein may be involved in mediating protein secretion by non-conventional routes.

\subsection{Other proteins}

\subsubsection{Imaginal disc growth factor}

Imaginal disc growth factors (IDGFs) were initially identified based on their potent activity on the cellular proliferation of imaginal discs, sac-like sheets of epithelial cells that develop into epidermal structures during metamorphosis to the adult (Bryant, 2001). Recent evidence suggests that IDGF is involved in nutritional signaling conveying information about the insect nutritional status to target tissues (Zhou et al., 2008; Wang et al., 2009). In 4th instar silkmoth, B. mori, haemolymph concentration of IDGF was approximately two times higher when caterpillars fed on artificial diet compared with lower nutritive value mulberry leaves (natural diet) (Zhou et al., 2008). BmIDGF expression in fat bodies of 4th instar silkworm $B$. mori caterpillars decreased in starved insects and sharply increased $24 \mathrm{~h}$ after re-feeding (Wang et al., 2009). Therefore, IDGF levels appear to be highly regulated by nutrition. Two homologues of IDGF were identified in S. exigua (Table 1). One was identified in the labial salivary gland of insects fed on all three diets. The second homologue was only identified in labial salivary glands of caterpillars fed on the 33:30 artificial diet. Therefore, IDGF levels in S. exigua caterpillar labial salivary glands also appear to be closely correlated with insect nutritional status.

\subsubsection{Digestive enzyme inhibitors: ribonuclease L inhibitor homolog and trypsin inhibitor}

Ribonucleases are often a component of saliva and may be a defensive strategy against ingested dsRNA viral pathogens or involved in digestion (Rampias et al., 2003; Maeda et al., 2005). In rat salivary parotid glands, ribonuclease $\mathrm{L}$ is found associated with an inhibitor which is removed before secretion (Robinovitch et al., 1968). Ribonuclease activity has been found in insect saliva and the presence of a ribonuclease $L$ inhibitor identified in $S$. exigua labial saliva in this study suggests that a similar mechanism is present in caterpillar saliva (Table 1) (Musser et al., 2002b).

Trypsin inhibitor was identified in caterpillar labial salivary glands, regardless of the diet fed (Table 1). A Kunitz-type protease inhibitor has been identified as secreted from prepupal Drosophila melanogaster salivary glands where it possibly plays a role regulating proteolytic activities during metamorphosis (Kress et al., 2004). Serine proteinase inhibitors (Serpins) have been identified in the salivary glands of numerous blood-feeding arthropods, such as tick (A. americanum and I. ricinus) and the tse-tse fly (Glossina morsitans) (Attardo et al., 2006; Alves-Silva et al., 2010; Chalaire et al., 2011). Proteases, such as trypsin, have been identified in salivary glands and secretions of a number of arthropods (Zhu et al., 2003; Oliveira et al., 2006; Francischetti et al., 2007; Meiser et al., 2010); therefore, it is possible, that similar to the ribonuclease $\mathrm{L}$ inhibitor, this protein binds to and inhibits the salivary digestive enzyme trypsin when in the salivary gland and is removed upon salivary secretion.

\subsubsection{Arylphorin}

Arylphorins are aromatic amino acid-rich proteins, predominantly synthesized in the fat body but also in tissues such as muscle, epidermis and the salivary glands, which act as storage proteins and are implicated in gut-associated stem cell proliferation (Webb and Riddiford, 1988; Blackburn et al., 2004). This protein was only detected in labial salivary glands of caterpillars fed on the protein-rich diet (33:30), which reflects the availability of excess amino acids on this diet that can be stored as arylphorins (Table 1). Recently, this protein has also been identified as a major protein in the labial and mandibular salivary glands of $V$. glonerilla caterpillars (de la Paz Celorio-Mancera et al., 2012).

\subsubsection{Thiol peroxiredoxin}

Peroxiredoxin, or thioredoxin peroxidase, is an antioxidant enzyme that uses thiols as reducing equivalents to eliminate the cellular reactive oxygen species hydrogen peroxide $\left(\mathrm{H}_{2} \mathrm{O}_{2}\right)$ (Hofmann et al., 2002). Recently, peroxiredoxins have also been shown to play important and diverse roles in redox cellular signaling. For example, in mammals, ER-associated peroxiredoxin IV oxidizes and further activates PDI, in the presence of $\mathrm{H}_{2} \mathrm{O}_{2}$, to accelerate protein folding (Zito et al., 2010). Peroxiredoxins are also involved in the redox regulation of V-type ATPases (Tavakoli et al., 2001). Peroxiredoxin is expressed in silk glands of $B$. mori caterpillars and fat body expression levels increased in response to temperature or pathogen stresses (Lee et al., 2005; Wang et al., 2008). Thiol peroxiredoxin was also identified in salivary secretions of $H$. armigera caterpillars (de la Paz Celorio-Mancera et al., 2011). In the study conducted here, peroxiredoxin was only identified in the S. exigua labial salivary glands of caterpillars fed on the protein-rich 33p:30c artificial diet, not in those fed on 22p:20c or plant diet (Table 1 ).

\section{Discussion}

This research investigated the soluble proteome of caterpillar labial salivary glands and the effect of diet, particularly the nutritional p:c ratio, focusing on proteins involved in protein secretory pathways. Proteins were identified by nanoLC/ESI/MS/MS and peptide comparison to the NCBI non-redundant dataset based on the presence of $>2$ peptides and only considered present if they were identified in all three independent biological replications (Table 1). Over 130 soluble proteins were identified and, as expected, most proteins (>40\%) were identified in caterpillar labial salivary glands independently of diet (Fig. 1). Upon analysis of the Gene Ontology (GO) biological classifications, it was found that over $10 \%$ of the proteins identified in caterpillar labial salivary glands were associated with protein secretion (Figs. 2 and 3). As expected, a high degree of homology was seen when compared to well-characterized mammalian systems that allowed us to propose a basic model for protein export in insect models (Fig. 4).

In addition, diet-specific differences associated with the caterpillar sialome were observed (Fig. 1, Table 1). Plant nutritional quantity and quality (secondary metabolites, p:c quality, ratio and quantity) dramatically affects insect behaviour and physiology (Bede et al., 2007). Soluble labial salivary gland protein profile was compared in caterpillars fed one of three diets: 22p:20c, 30p:30c and the plant, $M$. trunctula. This includes two diets representing the self-selected p:c ratio of caterpillars of the beet armyworm, $S$. exigua (Merkx-Jacques et al., 2008): 22p:20c and 33p:30c where 22p:20c is of lower nutritional content than 33p:30c. Previous research in our laboratory has shown that dietary nutritional quality affects the gene expression and enzyme activity of the labial salivary gland-associated glucose oxidase (GOX) (Afshar et al., 2010). This is significant given that GOX activity has been implicated in the caterpillar's ability to prevent the induction of plant defense 
responses (Musser et al., 2002a; Weech et al., 2008). Afshar et al. (2010) showed that SeGOX gene expression reflected changing dietary carbohydrate content, but GOX activity indicated that dietary protein also was involved in the regulation of enzyme activity; it was assumed that this suggested a post-transcriptional modification. However, the results of this study on the caterpillar labial salivary gland proteome sheds a different interpretation of these results. Perhaps, the lower GOX activity reflects active secretion processes occurring in caterpillars fed plants or 22p:20c. GA3PDH is associated with the salivary glands of caterpillars fed the pro- tein-poor diets, plant or 22p:20c, suggesting links between glycolysis and protein secretion. Other nutrient stress-associated proteins, such as PPI and GRP94/endoplasmin, were also identified in these labial salivary glands (Lee, 2001; Gupta and Tuteja, 2011). Many proteins associated with ERAD and also stress-related chaperones, such as HSP90, were also identified in labial salivary glands of caterpillars fed on plant or the 22p:20c artificial diet. In comparison, proteins associated with retrograde transport, such as RAB7, and non-classical protein secretion, were identified in labial salivary glands of caterpillars fed 33p:30c. Proteins associated with

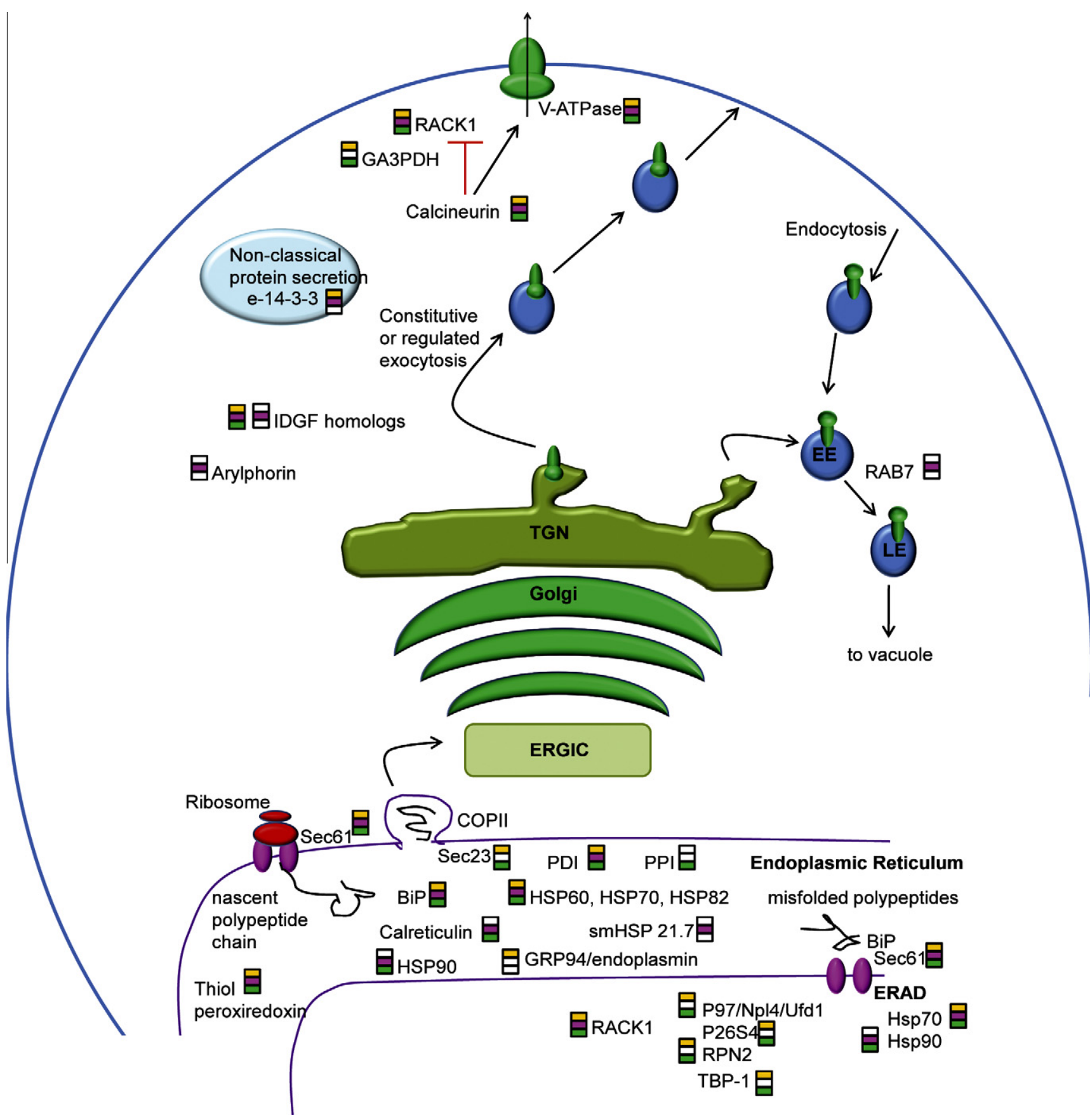

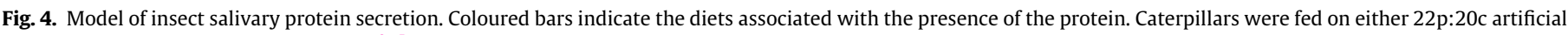

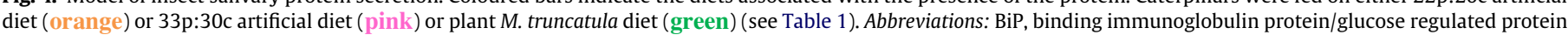

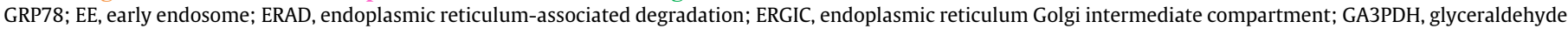

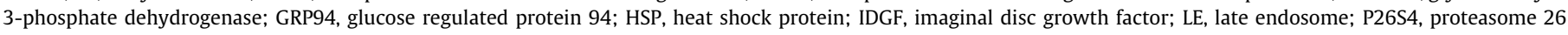

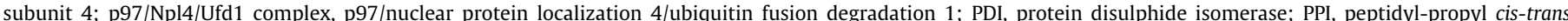

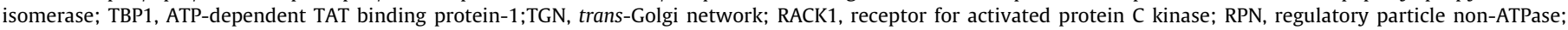
V-ATPase, vacuolar-ATPase. (For interpretation of the references to colour in this figure legend, the reader is referred to the web version of this article.) 
storage and nutritional signaling were also identified in these caterpillars fed a protein-rich diet (Webb and Riddiford, 1988; Shingleton et al., 2008). Therefore, based on the proteins associated with caterpillars reared on different dietary regimes, caterpillars fed nutritionally-poorer diets may have accelerated pathways leading to ER-mediated vesicular secretions compared to those fed 33p:30c (Table 1, Fig. 4).

\section{Acknowledgements}

We thank Dominique Brown, Pratap Paudel and Mei Xiao for assistance with data analysis. We are grateful to Dr. Armando Jardim and two anonymous reviewers for insightful comments to the manuscript. This research was funded by a grant to J.C.B. from the Natural Sciences and Engineering Research Council.

\section{Appendix A. Supplementary data}

Supplementary data associated with this article can be found, in the online version, at http://dx.doi.org/10.1016/j.jinsphys.2013. 01.002 .

\section{References}

Abcouwer, S.F., Marjon, P.L., Loper, R.K., Vander Jagt, D.L., 2002. Response of VEGF expression to amino acid deprivation and inducers of endoplasmic reticulum stress. Investigative Ophthalmology \& Visual Science 43, 2791-2798.

Afshar, K., Dufresne, P.J., Pan, L., Merkx-Jacques, M., Bede, J.C., 2010. Diet-specific salivary gene expression and glucose oxidase activity in Spodoptera exigua (Lepidoptera: Noctuidae) larvae. Journal of Insect Physiology 56, 1798-1806.

Ali, D.W., 1997. The aminergic and peptidergic innervation of insect salivary glands. Journal of Experimental Biology 200, 1941-1949.

Alves-Silva, J., Ribeiro, J.M.C., Van Den Abbeele, J., Attardo, G., Hao, Z.R., Haines, L.R., Aksoy, S., Lehane, M.J., 2010. An insight into the sialome of Clossina morsitans morisitans. BMC Genomics 11, 213.

Arcà, B., Lombardo, F., Francischetti, I.M.B., Pham, V.M., Mestres-Simon, M., Andersen, J.F., Ribeiro, J.M.C., 2007. An insight into the sialome of the adult female mosquito Aedes albopictus. Insect Biochemistry and Molecular Biology 37, 107-127.

Attardo, G.M., Strickler-Dinglasan, P., Perkin, S.A.H., Caler, E., Bonaldo, M.F., Soares, M.B., El-Sayeed, N., Aksoy, S., 2006. Analysis of fat body transcriptome from the adult tsetse fly, Clossina morsitans morsitans. Insect Molecular Biology 15, 411424

Babic, B., Poisson, A., Darwish, S., Lacasse, J., Merkx-Jacques, M., Despland, E., Bede, J.C., 2008. Influence of dietary nutritional composition on caterpillar salivary enzyme activity. Journal of Insect Physiology 54, 286-296.

Bagola, K., Mehnert, M., Jarosch, E., Sommer, T., 2011. Protein dislocation from the ER. Biochemica et Biophysica Acta Biomembranes 1808, 925-936.

Baksh, S., Burns, K., Andrin, C., Michalak, M., 1995. Interaction of calreticulin with protein disulfide isomerase. Journal of Biological Chemistry 270, 31338-31344.

Baumann, O., Walz, B., 2011. The blowfly salivary gland - a model for analyzing the regulation of plasma membrane V-ATPase. Journal of Insect Physiology 58, 450 458

Bede, J.C., McNeil, J.N., Tobe, S.S., 2007. The role of neuropeptides in caterpillar nutritional ecology. Peptides 28, 185-196.

Blackburn, M.B., Loeb, M.J., Clark, E., Jaffe, H., 2004. Stimulation of midgut stem cell proliferation by Manduca sexta a-arylphorin. Archives of Insect Biochemistry and Physiology 55, 26-32.

Braakman, I., Bulleid, N.J., 2011. Protein folding and modification in the mammalian endoplasmic reticulum. Annual Review of Biochemistry 80, 71-99.

Bradford, M.M., 1976. Rapid and sensitive method for quantitation of microgram quantities of protein utilizing the principle of protein-dye binding. Analytical Biochemistry 72, 248-254.

Brandon, N.J., Jovanovic, J.N., Smart, T.G., Moss, S.J., 2002. Receptor for activated C kinase-1 facilitates protein kinase C-dependent phosphorylation and functional modulation of $\mathrm{GABA}_{\mathrm{A}}$ receptors with the activation of G-protein-coupledreceptors. The Journal of Neuroscience 22, 6353-6361.

Brunner, Y., Schvartz, D., Couté, Y., Sanchez, J.-C., 2009. Proteomics of regulated secretory organelles. Mass Spectrometry Reviews 28, 844-867.

Bryant, P.J., 2001. Growth factors controlling imaginal disc growth in Drosophila. Novartis Foundation Symposium 237, 194-202.

Buchner, J., 1999. Hsp90 and Co. - a holding for folding. Trends in Biological Sciences 24, 136-141.

Burgoyne, R.D., Morgan, A., 2003. Secretory granule exocytosis. Physiological Reviews 83, 581-632.

Carolan, J.C., Fitzroy, C.I.J., Ashton, P.D., Douglas, A.E., Wilkinson, T.L., 2009. The secreted salivary proteome of the pea aphid Acyrthosiphon pisum characterized by mass spectroscopy. Proteomics 9, 2457-2467.
Carreño, F.R., Goñi, C.N., Castro, L.M., Ferro, E.S., 2005. 14-3-3 epsilon modulates the stimulated secretion of endopeptidase 24.15 . Journal of Neurochemistry 93,10 25

Chalaire, K.C., Kim, T.K., Garcia-Rodriguez, H., Mulenga, A., 2011. Amblyomma americanum (L.) (Acari: Ixodidae) tick salivary gland serine protease inhibitor (serpin) 6 is secreted into tick saliva during tick feeding. Journal of Experimental Biology 214, 665-673.

Chamberlain, L.H., Roth, D., Morgan, A., Burgoyne, R.D., 1995. Distinct effects of aSNAP, 14-3-3 proteins, and calmodulin on priming and triggering of regulated exocytosis. Journal of Cell Biology 130, 1063-1070.

Christensen, T.A., Itagaki, H., Teal, P.E.A., Jasensky, R.D., Tumlinson, J.H., 1991. Innervation and neural regulation of the sex pheromone gland in female Heliothis moths. Proceedings of the National Academy of Sciences 88, 49714975.

Chung, J.Y., Lim, S.W., Hong, Y.J., Hwang, S.O., Lee, G.M., 2004. Effect of doxycyclineregulated calnexin and calreticulin expression on specific thrombopoietin productivity of recombinant Chinese hamster ovary cells. Biotechnology and Bioengineering 85, 539-546.

Cooper, W.R., Dillwith, J.W., Puterka, G.J., 2010. Salivary proteins of Russian wheat aphid (Hemiptera: Aphididae). Environmental Entomology 39, 223-231.

Courtiade, J., Muck, A., Svatoš, A., Heckel, D.G., Pauchet, Y., 2011. Comparative proteomic analysis of Helicoverpa armigera cells undergoing apoptosis. Journal of Proteome Research 10, 2633-2642.

Csukai, M., Mochly-Rosen, D., 1999. Pharmacological modulation of protein kinase C isozymes: the role of RACKs and subcellular localization. Pharmacological Research 39, 253-259.

Daimon, T., Taguchi, T., Meng, Y., Katsuma, S., Mita, K., Shimada, T., 2008. $\beta-$ Fructofuranosidase genes of the silkworm, Bombyx mori. Insights into enzymatic adaptation of $B$. mori to toxic alkaloids in mulberry latex. The Journal of Biological Chemistry 283, 15271-15279.

Das, S., Radtke, A., Choi, Y.-J., Mendes, A.M., Valenzuela, J.G., Dimopoulos, G., 2010 Transcriptomic and functinal analysis of the Snopheles gambiae salivary gland in relation to blood feeding. BMC Genomics 11, 566.

Davis, R., Schooley, K., Rasmussen, B., Thomas, J., Reddy, P., 2000. Effect of PDI overexpression on recombinant protein secretion in CHO cells. Biotechnology Progress 16, 736-743.

de la Paz Celorio-Mancera, M., Courtiade, J., Muck, A., Heckel, D.G., Musser, R.O. Vogel, H., 2011. Sialome of a generalist lepidopteran herbivore: identification of transcripts and proteins from Helicoverpa armigera labial salivary glands. Plos One 6, e26676.

de la Paz Celorio-Mancera, M., Sundmalm, S.M., Vogel, H., Rutishauser, D., Ytterberg A.J., Zubarev, R.A., Janz, N., 2012. Chemosensory proteins, major salivary factors in caterpillar mandibular glands. Insect Biochemistry and Molecular Biology 42, 796-805.

Diekmann, Y., Seixas, E., Gouw, M., Tavares-Cadete, F., Seabra, M.C., Pereira-Leal, J.B. 2011. Thousands of Rab GTPases for the cell biologist. PLOS Computational Biology 7, e1002217.

Dudek, J., Benedix, J., Cappel, S., Greiner, M., Jalal, C., Müller, L., Zimmermann, R. 2009. Functions and pathologies of BiP and its interaction partners. Cellular and Molecular Life Science 66, 1556-1569.

Eichenseer, H., Mathew, M.C., Jian, L.B., Murphy, J.B., Felton, G.W., 1999. Salivary glucose oxidase: multifunctional roles for Helicoverpa zea. Archives of Insect Biochemistry and Physiology 42, 99-109.

Eichenseer, H., Mathew, M.C., Powell, J.S., Felton, G.W., 2010. Survey of a salivary effector in caterpillars: glucose oxidase variation and correlation with host range. Journal of Chemical Ecology 36, 885-897.

Eletto, D., Dersh, D., Argon, Y., 2010. GRP94 in ER quality control and stress responses. Seminars in Cell \& Developmental Biology 21, 479-485.

Ellgaard, L., Helenius, A., 2003. Quality control in the endoplasmic reticulum. Nature Reviews: Molecular Cell Biology 4, 181-191.

Feder, M.E., Hofmann, G.E., 1999. Heat-shock proteins, molecular chaperones and the stress response: evolutionary and ecological physiology. Annual Reviews in Physiology 61, 243-282.

Felton, G.W., 1996. Nutritive quality of plant protein: sources of variation and insect herbivore responses. Archives of Insect Biochemistry and Physiology 32, 107130.

Felton, G.W., 2008. Caterpillar Secretions and Induced Plant Responses. Springer Hochenheim, Germany.

Ferreira, C.A.S., Vaz, I.D., da Silva, S.S., Haag, K.L., Valenzuela, J.G., Masuda, A., 2002 Cloning and partial characterization of a Boophilus microplus (Acari: Ixodidae) calreticulin. Experimental Parasitology 101, 25-34.

Francischetti, I.M.B., Lopes, A.H., Dias, F.A., Pham, V.M., Ribeiro, J.M.C., 2007. An insight into the sialotranscriptome of the seed-feeding bug, Oncopeltus fasciatus. Insect Biochemistry and Molecular Biology 37, 903-910.

Frickel, E.M., Frei, P., Bouvier, M., Stafford, W.F., Helenius, A., Glockshuber, R. Ellgaard, L., 2004. ERp57 is a multifunctional thiol-disulfide oxidoreductase. Journal of Biological Chemistry 279, 18277-18287.

Fromme, J.C., Orci, L., Schekman, R., 2008. Coordination of COPII vesicle trafficking by Sec23. Trends in Cell Biology 18, 330-336.

Fukuda, M., 2008. Regulation of secretory vesicle traffic by Rab small GTPases. Cellular and Molecular Life Science 65, 2801-2813.

Garrett, M.D., Zahner, J.E., Cheney, C.M., Novick, P.J., 1994. GD1 encodes a GDP dissociation inhibitor that plays an essential role in the yeast secretory pathway. The EMBO Journal 13, 1718-1728.

Gasser, B., Saloheimo, M., Rinas, U., Dragosits, M., Rodríguez-Carmona, E., Baumann, K., Giuliani, M., Parrilli, E., Branduardi, P., Lang, C., Porro, D., Ferrer, P., Tutino, 
M.L., Mattanovich, D., Villaverde, A., 2008. Protein folding and conformational stress in microbial cells producing recombinant proteins: a host comparative overview. Microbial Cell Factories 7, 11-28.

Gilbert, P.M., Burd, C.G., 2001. GDP dissociation inhibitor domain II required for Rab GTPase recycling. Journal of Biological Chemistry 276, 8014-8020.

Glaser, P.E., Han, X.L., Gross, R.W., 2002. Tubulin is the endogenous inhibitor of the glyceraldehyde 3-phosphate dehydrogenase isoform that catalyzes membrane fusion: implications for the coordinated regulation of glycolysis and membrane fusion. Proceedings of the National Academy of Sciences of the United States of America 99, 14104-14109.

Gomez, T.A., Kolawa, N., Gee, M., Sweredoski, M.J., Deshaies, R.J., 2011. Identification of a functional docking site in the Rpn1 LRR domain for the UBA-UBL domain protein Ddi1. BMC Biology 9, 33.

Goo, T.W., Yun, E.Y., Kim, S.W., Choi, K.H., Kang, S.W., Kwon, K., Yu, K., Kwon, O.-Y., 2008. Bombyx mori protein disulfide isomerase enhances the production of nuecin, an antibacterial protein. BMB Reports 41, 400-403.

Goody, R.S., Rak, A., Alexandrov, K., 2005. The structural and mechanistic basis for recycling of Rab proteins between membrane compartments. Cellular and Molecular Life Science 62, 1657-1670.

Gorr, S.U., Venkatesh, S.G., Darling, D.S., 2005. Partoid secretory granules: crossroads of secretory pathways and protein storage. Journal of Dental Research 84, 500-509.

Greensfield, J.J.A., High, S., 1999. The Sec61 complex is located both in the ER and the ER-golgi intermediate compartment. Journal of Cell Science 112, 1477 1486.

Grosshans, B.L., Ortiz, D., Novick, P., 2006. Rabs and their effectors: achieving specificity in membrane traffic 103, 11821-11827.

Gupta, D., Tuteja, N., 2011. Chaperones and foldases in endoplasmic reticulum stress signaling in plants. Plant Signaling \& Behavior 6, 232-236.

Harata, N.C., Aravanis, A.M., Tsien, R.W., 2006. Kiss-and-run and full-collapse fusion as modes of exo-endocytosis in neurosecretion. Journal of Neurochemistry 97 1546-1570.

Harmel, N., Létocart, E., Cherqui, A., Giordanego, P. Mazzucchelli, G., Guillonneau, F. De Pauw, E., Haubruge, E., Francis, F., 2008. Identification of aphid salivary proteins: a proteomic investigation of Myzus persicae. Insect Molecular Biology $17,165-174$

Herrmann, J., Lerman, L.O., Lerman, A., 2007. Ubiquitin and ubiquitin-like proteins in protein regulation. Circulation Research 100, 1276-1291

Heydari, A.R., Wu, B., Takahashi, R., Strong, R., Richardson, A., 1993. Expression of heat shock protein 70 is altered by age and diet at the level of transcription. Molecular and Cellular Biology 13, 2909-2918.

Hirokawa, N., Noda, Y., Okada, Y., 1998. Kinesin and dynein superfamily proteins in organelle transport and cell division. Current Opinion in Cell Biology 10, 60 73.

Hofmann, B., Hecht, H.-J., Flohé, L., 2002. Peroxiredoxins. Biological Chemistry 383, 347-364.

Hosoda, A., Tokuda, M., Akai, R., Kohno, K., Iwawaki, T., 2010. Positive contribution of ERdj5/JPDI to endoplasmic reticulum protein quality control in the salivary gland. Biochemistry Journal 425, 117-125.

House, C.R., Ginsborg, B.L., 1985. Salivary Gland. Comprehensive Insect Physiology, Biochemistry and Pharmacology. Pergamon Press, New York, pp. 195-223.

Hu, Y.-H., Leung, D.W.M., Kang, L., Wang, C.Z., 2008. Diet factors responsible for the change of the glucose oxidase activity in labial salivary glands of Helicoverpa zea. Archives of Insect Biochemistry and Physiology 68, 113-121.

Inan, M., Aryasomayajula, D., Sinha, J., Meagher, M.M., 2006. Enhancement of protein secretion in Pichia pastoris by overexpression of protein disulfide isomerase. Biotechnology and Bioengineering 93, 771-778.

Jaworski, D.C., Simmen, F.A., Lamoreaux, W., Coons, L.B., Muller, M.T., Needham, G.R., 1995. A secreted calreticulin protein in ixodid tick (Amblyomma americanum) saliva. Journal of Insect Physiology 41, 369-375.

Jordens, I., Marsman, M., Kuijl, C., Neefjes, J., 2005. Rab proteins, connecting transport and vesicle fusion. Traffic 6, 1070-1077.

Kalume, D.E., Okulate, M., Zhong, J., Reddy, R., Suresh, S., Deshpande, A., Kumar, N. Pandey, A., 2005. A proteomic analysis of salivary glands of female Anopheles gambiae mosquito. Proteomics 5, 3765-3777.

Kane, P.M., Parra, K.J., 2000. Assembly and regulation of the yeast vacuolar $\mathrm{H}^{+}$ ATPase. The Journal of Experimental Biology 203, 81-87.

Kay, J.E., 1996. Structure-function relationships in the FK506-binding protein (FKBP) family of peptidyprolyl cis-trans isomerases. Biochemistry Journal 314 361-385.

Kim, T., Gondré-Lewis, M.C., Arnaoutova, I., Loh, Y.P., 2006. Dense-core secretory granule biogenesis. Physiology 21, 124-133.

Knizetova, P., Vancova, I., Kocakova, P., Slovak, M., Proost, P., Kopacek, J., 2006. New member of the protein disulfide isomerase (PDI) family identified in Amblyomma variegatum tick. Insect Biochemistry and Molecular Biology 36, 943-953.

Kress, H., Jarrin, A., Thüroff, E., Saunders, R., Weise, C., Schmidt am Busch, M., Knapp E.-W., Wedde, M., Vilcinskas, A., 2004. A Kunitz type protease inhibitor related protein is synthesized in Drosophila prepupal salivary glands and released into the moulting fluid during pupation. Insect Biochemistry and Molecular Biology 34, 855-869.

Lam, Y.A., Lawson, T.G., Velayutham, M., Zweier, J.L., Pickart, C.M., 2002. A proteasomal ATPase subunit recognizes the polyubiquitin degradation signal. Nature 416, 763-767.

Landais, I., Pommet, J.-M., Mita, K., Nohata, J., Gimenez, S., Fournier, P., Devauchelle G., Duonor-Cerutti, M., Ogliastro, M., 2001. Characterization of the cDNA encoding the $90 \mathrm{kDa}$ heat-shock protein in the Lepidoptera Bombyx mori and Spodoptera frugiperda. Gene 271, 221-223.

Lander, G.C., Estrin, E., Matyskiela, M.E., Bashore, C., Nogales, E., Martin, A., 2012. Complete subunit architecture of the proteasome regulatory particle. Nature 482, 186-191.

Lee, A.S., 2001. The glucose-regulated proteins: stress induction and clinical applications. Trends in Biological Sciences 26, 504-510.

Lee, J., Lee, J., Bong Gun, J., 2011. Drosophila arf72A acts as an essential regulator of endoplasmic reticulum quality control and supresses autosomal-dominant retinopathy. The International Journal of Biochemistry \& Cell Biology 43, 13921401.

Lee, K.P., Behmer, S.T., Simpson, S.J., Raubenheimer, D., 2002. A geometric analysis of nutrient regulation in the generalist caterpillar Spodoptera littoralis (Boisduval). Journal of Insect Physiology 48, 655-665.

Lee, K.P., Raubenheimer, D., Behmer, S.T., Simpson, S.J., 2003. A correlation between macronutrient balancing and insect host-plant range: evidence for the specialist caterpillar Spodoptera exempta (Walker). Journal of Insect Physiology 49, 1161-1171.

Lee, K.S., Kim, S.R., Park, N.S., Kim, I., Kang, P.D., Sohn, B.H., Choi, K.H., Kang, S.W., Je, Y.H., Lee, S.M., Sohn, H.D., Jin, B.R., 2005. Characterization of a silkworm thioredoxin peroxidase that is induced by external temperature stimulus and viral infection. Insect Biochemistry and Molecular Biology 35, 73-84.

Li, Z.-W., Li, X., Yu, Q.-Y., Xiang, Z.-H., Kishino, H., Zhang, Z., 2009. The small heat shock protein (sHSP) genes in the silkworm, Bombyx mori, and comparative analysis with other insect sHSP genes. BMC Evolutionary Biology 9, 215.

Liao, M., Hatta, T., Umemiya, R., Huang, P., Jia, H., Gong, H., Zhou, J., Nishikawa, Y., Xuan, X., Fujisaki, K., 2007. Identification of three disulfide isomerase members from Haemaphysalis longicornis tick. Insect Biochemistry and Molecular Biology 37, 641-654.

Liu, F., Cui, L., Cox-Foster, D., Felton, G.W., 2004. Characterization of a salivary lysozyme in larval Helicoverpa zea. Journal of Chemical Ecology 30, 24392457.

Liu, Y.V., Hubbi, M.E., Pan, F., McDonald, K.R., Mansharamani, M., Cole, R.N., Liu, J.O., Semenza, G.L., 2007. Calcineurin promotes hypoxia-inducible factor 1a expression by dephosphorylating RACK1 and blocking RACK1 dimerization. The Journal of Biological Chemistry 282, 37064-37073.

Lu, M., Ammar, D., Ives, H., Albrecht, F., Gluck, S.L., 2007. Physical interaction between aldolase and vacuolar $\mathrm{H}^{+}$-ATPase is essential for the assembly and activity of the proton pump. The Journal of Biological Chemistry 282, 2449524503.

Maeda, T., Lee, J.M., Miyagawa, Y., Koga, K., Kawaguchi, Y., Kusakabe, T., 2005. Cloning and characterization of a ribonuclease L inhibitor from the silkworm, Bombyx mori. DNA Sequence 16, 21-27.

Marshansky, V., Futai, M., 2008. The V-type $\mathrm{H}^{+}$-ATPase in vesicular trafficking: targeting, regulation and function. Current Opinion in Cell Biology 20, 415-426.

Mathews, M.C., Summers, C.B., Felton, G.W., 1997. Ascorbate peroxidase: a novel antioxidant enzyme in insects. Archives of Insect Biochemistry and Physiology 34, 57-68.

McCahill, A., Warwicker, J., Bolger, G.B., Houslay, M.D., Yarwood, S.J., 2002. The RACK1 scaffold protein: a dynamic cog in cell response mechanisms. Molecular Pharmacology 62, 1261-1273.

Mehnert, M., Sommer, T., Jarosch, E., 2010. ERAD ubiquitin ligases: multifunctional tools for protein quality control and waste disposal in the endoplasmic reticulum. Bioessays 32, 905-913.

Meiser, C.K., Piechura, H., Meyer, H.E., Warscheid, B., Schaub, G.A., Balczun, C., 2010. A salivary serine protease of the haematophagous reduviid Panstrongylus megistus: sequence characterization, expression pattern and characterization of proteolytic activity. Insect Molecular Biology 19, 409-421.

Menzendorfer, H., Reineke, S., Zhao, X.-F., Jacobmeier, B., Harvey, W.R., Wieczorek, H., 2000. The multigene family of the tobacco hornworm V-ATPase: novel subunits A, C, D, H, and putative isoforms. Biochimica et Biophysica Acta 1467, 369-379.

Merkx-Jacques, M., Bede, J.C., 2005. Influence of diet on the larval beet armyworm, Spodoptera exigua, glucose oxidase activity. Journal of Insect Science 5, 48.

Merkx-Jacques, M., Despland, E., Bede, J.C., 2008. Nutrient utilization by caterpillars of the generalist beet armyworm, Spodoptera exigua. Physiological Entomology 33, 51-61.

Michalak, M., Groenendyk, J., Szabo, E., Gold, L.I., Opas, M., 2009. Calreticulin, a multi-process calcium-buffering chaperone of the endoplasmic reticulum. Biochemistry Journal 417, 651-666.

Mohan, C., Park, S.H., Chung, J.Y., Lee, G.M., 2007. Effect of doxycycline-regulated protein disulfide isomerase expression on the specific productivity of recombinant $\mathrm{CHO}$ cells: thrombopoietin and antibody. Biotechnology and Bioengineering 98, 611-615.

Morgan, A., Burgoyne, R.D., Barclay, J.W., Craig, T.J., Prescott, G.R., Ciufo, L.F., Evans, G.J.O., Graham, M.E., 2005. Regulation of exocytosis by protein kinase C. Biochemical Society Transactions 33, 1341-1344.

Morrison, D., 1994. 14-3-3: Modulators of signaling proteins? Science 266, 56-57.

Musser, R.O., Hum-Musser, S.M., Eichenseer, H., Peiffer, M., Ervin, G., Murphy, J.B., Felton, G.W., 2002a. Caterpillar saliva beats plant defences: anew weapon emerges in the evolutionary arms race between plants and herbivores. Nature 416, 599-600.

Musser, R.O., Hum-Musser, S.M., Slaten-Bickford, S.E., Felton, G.W., Gergerich, R.C., $2002 \mathrm{~b}$. Evidence that ribonuclease activity present in beetle regurgitant is found to stimulate virus resistance in plants. Journal of Chemical Ecology 28, 1691-1696. 
Nashida, T., Yoshie, S.Y., Imai, A., Shimomura, H., 2004. Presence of cytoskeleton proteins in parotid glands and their roles during secretion. Archives of Oral Biology 49, 975-982.

Nene, V., Lee, D., Quackenbush, J., Skilton, R., Mwaura, S., Gardner, M.J., Bishop, R., 2002. AvGI, an index of genes transcribed in the salivary glands of the ixodid tick Amblyomma veriegatum. International Journal of Parasitology 32, 14471456

Nishi, T., Forgac, M., 2002. The vacuolar $\left(\mathrm{H}^{+}\right)$-ATPases - nature's most versatile proton pumps. Nature Reviews: Molecular Cell Biology 3, 94-103.

Nishikawa, S., Fewell, S.W., Kato, Y., Brodsky, J.L., Endo, T., 2001. Molecular chaperones in the yeast endoplasmic reticulum maintain the solubility of proteins for retrotranslocation and degradation. Journal of Cell Biology 153, 1061-1069.

Oliveira, J.A., Oliveira, M.G.A., Guedes, R.N.C., Soares, M.J., 2006. Morphology and preliminary enzyme characterization of the salivary glands from the predatory bug Podisus nigrispinus (Heteroptera: Pentatomidae). Bulletin of Entomological Research 96, 251-258.

Owens-Grillo, J.K., Czar, M.J., Hutchison, K.A., Hoffman, K., Perdew, G.H., Pratt, W.B., 1996. A model of protein targeting mediated by immunophilins and other proteins that bind to hsp90 via tetratricopeptide repeat domains. Journal of Biological Chemistry 271, 13468-13475.

Park, S., Tian, G., Roelofs, J., Finley, D., 2010. Assembly manual for the proteasome regulatory particle: the first draft. Biochemical Society Transactions 38, 6-13.

Parthasarathy, R., Gopinathan, K.P., 2005. Comparative analysis of the development of the mandibular salivary glands and the labial salivary glands in the mulberry silkworm, Bombyx mori. Gene Expression Patterns 5, 323-339.

Pfeffer, S.R., 2010. How the golgi works: a cisternal progenitor model. Proceedings of the National Academy of Sciences 107, 19614-19618

Pollock, S., Kozlov, G., Pelletier, M.-F., Trempe, J.-F., Jansen, G., Sitnikov, D., Bergeron, J.J.M., Gehring, K., Ekeil, I., Thomas, D.Y., 2004. Specific interaction of ERp57 and calnexin determined by NMR spectroscopy and an ER two-hybrid system. The EMBO Journal 23, 1020-1029.

Pye, V.E., Beuron, F., Keetch, C.A., McKeown, C., Robinson, C.V., Meyer, H.H., Zhang, X., Freemont, P.S., 2007. Structural insights into the p97-Ufd1-NpI4 complex. Proceedings of the National Academy of Sciences of the United States of America 104, 467-472.

Raffaniello, R., Fedorova, D., Ip, D., Rafiq, S., 2009. Hsp90 co-localizes with Rab-GDI1 - and regulates antagonist-induced amylase release inAR42J cells. Cellular Physiology and Biochemistry 24, 369-378.

Rampias, T.N., Sideris, D.C., Fragoulis, E.G., 2003. CC RNase: the Ceratitis capitata ortholog of a novel highly conserved protein family in metazoans. Nucleic Acids Research 31, 3092-3100.

Ribeiro, J.M.C., Charlab, R., Pham, V.M., Garfield, M.K., Valenzuela, J.G., 2004. An insight into the salivary transcriptome and proteome of the adult female mosquito Culex pipiens quinquefasciatus. Insect Biochemistry and Molecular Biology 34, 543-563.

Ribeiro, J.M.C., Francischetti, I.M.B., 2003. Role of arthropod saliva in blood feeding: sialome and post-sialome perspectives. Annual Reviews of Entomology 48, 7388.

Ricard, C.S., Jakubowski, J.M., Verbsky, J.W., Barbieri, M.A., Lewis, W.M., Fernandez, G.E., Vogel, M., Tsou, C., Prasad, V., Stahl, P.D., Waksman, G., Cheney, C.M., 2001. Drosophila Rab GDI mutants disrupt development but have normal Rab membrane extraction. Genesis 31, 17-29.

Robinovitch, M.R., Sreebny, L.M., Smuckler, E.A., 1968. Ribonuclease and ribonuclease inhibitor of the rat parotid gland and its secretion. The Journal of Biological Chemistry 243, 3441-3446.

Rosenzweig, R., Bronner, V., Zhang, D., Fushman, D., Glickman, M.H., 2012. Rpn1 and Rpn2 coordinate ubiquitin processing factors at the proteasome. Journal of Biological Chemistry 287, 14659-14671.

Roth, D., Birkenfeld, J., Betz, H., 1999. Dominant-negative alleles of 14-3-3 proteins cause defects in actin organization and vesicle targeting in the yeast Saccharomyces cerevisiae. FEBS Letters 460, 411-416.

Ruan, Y., Guo, L., Qiao, Y., Hong, Y., Zhou, L., Sun, L., Wang, L., Zhu, H., Wang, L., Yun, X., Xie, J., Gu, J., 2009. RACK1 associates with CLEC-2 and promotes its ubiquitinproteasome degradation. Biochemical and Biophysical Research Communications 390, 217-222.

Ryoo, H.D., Steller, H., 2007. Unfolded protein response in Drosophila - why another model can make it fly. Cell Cycle 6, 830-835.

Sakano, D., Li, B., Xia, Q., Yamamoto, K., Fujii, H., Aso, Y., 2006. Genes encoding small heat shock proteins of the silkworm, Bombyx mori. Bioscience Biotechnology \& Biochemistry 70, 2443-2450.

Schwartz, S.L., Cao, C., Pylypenko, O., Rak, A., Wandinger-Ness, A., 2007. Rab GTPases at a glance. Journal of Cell Science 120, 3905-3910.

Seddas, P., Boissinot, S., Strub, J.-M., Van Dorsselaer, A., Van Regenmortel, M.H.V., Pattus, F., 2004. Rack-1, GAPDH2, and actin: proteins of Myzus persicae potentially involved in the transcytosis of beet western yellows virus particles in the aphid. Virology 325, 399-412.

Shingleton, A.W., Mirth, C.K., Bates, P.W., 2008. Development model of static allometry in holometabolous insects. Proceedings of the Royal Society B 275, 1875-1885.

Simpson, S.J., Abisgold, J.D., 1985. Compensation by locusts for changes in dietary nutrients: behavioural mechanisms. Physiological Entomology 10 , 443-452.
Smith, D.M., Chang, S.C., Park, S., Finley, D., Cheng, Y., Goldberg, A.L., 2007. Docking of the proteasomal ATPases' carboxyl termini in the 20S proteasome's a ring opens the gate for substrate entry. Molecular Cell 27, 731-744.

Stein, M.-P., Dong, J., Wandinger-Ness, A., 2003. Rab proteins and endocytic trafficking: potential targets for therapeutic intervention. Advanced Drug Delivery Reviews 55, 1421-1437.

Stenmark, H., 2009. Rab GTPases as coordinators of vesicle traffic. Nature Reviews Molecular Cell Biology 10, 513-525.

Sumner, J.P., Dow, J.A.T., Earley, F.G.P., Klein, U., Jager, D., Wieczorek, H., 1995 Regulation of plasma membrane V-ATPase activity by dissociation of peripheral subunits. Journal of Biological Chemistry 270, 5649-5653.

Takahashi, K., Saski, T., Mammoto, A., Takaishi, K., Kameyama, T., Tsukita, S., Takai, Y., 1997. Direct interaction of the Rho GDP dissociation inhibitor with ezrin radixin/moesin initiates the activation of the Rho small G protein. Journal of Biological Chemistry 272, 23371-23375.

Tavakoli, N., Kluge, C., Golldack, D., Mimura, T., Dietz, T.J., 2001. Reversible redox control of plant vacuolar $\mathrm{H}^{+}$-ATPase activity is related to disulfide bridge formation in subunit E as well as subunit A. Plant Journal 2828, 51-59.

Tisdale, E.J., Fouad, A., Artalego, C.R., 2009. Rab2 utilizes glyceraldehyde-3phosphate dehydrogenase and protein kinase $\mathrm{Ci}$ to associate with microtubules and recruit dynein. Journal of Biological Chemistry 284, 58765884.

Tzivion, G., Avruch, J., 2001. 14-3-3 proteins: active cofactors in cellular regulation by serine/threonine phosphorylation. Journal of Biological Chemistry 277 3061-3064.

Um, J.W., Im, E., Park, J., Oh, Y., Min, B., Lee, H.J., Yoon, J.B., Chung, K.C., 2010. ASK1 negatively regulates the $26 \mathrm{~S}$ proteasome. The Journal of Biological Chemistry 285, 36434-36446

Valentijn, K.M., Gumkowski, F.D., Jamieson, J.D., 1999. The subapical actin cytoskeleton regulates secretion and membrane retrieval in pancreatic acinar cells. Journal of Cell Science 112, 81-96.

Valenzuela, J.G., Francischetti, I.M.B., Pham, V.M., Garfield, M.K., Ribeiro, J.M.C. 2003. Exploring the salivary gland transcriptome and proteome of the Anopheles stephensi mosquito. Insect Biochemistry and Molecular Biology 33, 717-732.

Voss, M., Fechner, L., Walz, B., Baumann, O., 2010. Calcineurin activity augment cAMP/PKA-dependent activation of V-ATPase in blowfly salivary glands. American Journal of Physiology. Cell Physiology 298, C1047-C1056.

Waldbauer, G.P., Friedman, S., 1991. Self-selection of optimal diets by insects Annual Review of Entomology 36, 43-63.

Wang, H.-B., Sakudoh, T., Kawasaki, H., Iwanaga, M., Araki, K., Fujimoto, H., Takada, N., Iwano, H., Tsuchida, K., 2009. Purification and expression analysis of imaginal disc growth factor in the silkworm, Bombyx mori. Journal of Insect Physiology 55, 1065-1071.

Wang, Q., Chen, K., Yao, O., Zhao, Y., Li, Y., Shen, H., Mu, R., 2008. Identification of characterization of a novel 1-Cys peroxiredoxin from silkworm, Bombyx mori Comparative Biochemistry and Physiology Part B 149, 176-182.

Warbrick-Smith, J., Behmer, S.T., Lee, K.P., Raubenheimer, D., Simpson, S.J., 2006 Evolving resistance to obesity in an insect. Proceedings of the National Academy of Sciences 103, 14045-14049.

Webb, B.A., Riddiford, L.M., 1988. Synthesis of 2 storage proteins during larval development of the tobacco hornworm, Manduca sexta. Developmental Biology 130, 671-681.

Weech, M.H., Chapleau, M., Pan, L., Ide, C., Bede, J.C., 2008. Caterpillar saliva interferes with induced Arabidopsis thaliana defence responses via the systemic acquired resistance pathway. Journal of Experimental Botany 59, 2437-2448.

Wieczorek, H., Beyenbach, K.W., Huss, M., Vitavska, O., 2009. Vacuolar-type proton pumps in insect epithelia. Journal of Experimental Biology 212, 1611-1619.

Wieczorek, H., Grüber, G., Harvey, W.R., Huss, M., Merzendorfer, H., Zeiske, W. 2000. Structure and regulation of insect plasma membrane $\mathrm{H}^{+}$V-ATPase. The Journal of Experimental Biology 203, 127-135.

Wolf, D.H., Stolz, A., 2012. The Cdc48 machine in endoplasmic reticulum associated protein degradation. Biochimica et Biophysica Acta 1823, 117-124.

Xu, G., Fang, Q.Q., Keirans, J.E., Duran, L.A., 2004. Cloning and sequencing of putative calreticulin complementary DNAs from four hard tick species. Journal of Parasitology 90, 73-78.

Xu, G., Fang, Q.Q., Sun, Y., Keirans, J.E., Durdan, L.A., 2005. Hard tick calreticulin (CRT) gene coding regions have only one intron with conserved regions and variable sizes. Journal of Parasitology 91, 1326-1331.

Zhang, W., Zhao, H.L., Xue, C., Xiong, X.H., Yao, X.Q., Li, X.Y., Chen, H.P., Xiu, Z.M. 2006. Enhanced secretion of heterologous proteins in Pichia pastoris following overexpression of Saccharomyces cerevisiae chaperone proteins. Biotechnology Progress 22, 1090-1095.

Zhou, Z.-H., Yang, H.-J., Chen, M., Lou, C.-F., Zhang, Y.-Z., Chen, K.-P., Wang, Y., Yu, M.-L., Yu, F., Li, J.-Y., Zhong, B.-X., 2008. Comparative proteomic analysis between the domesticated silkworm (Bombyx mori) reared on fresh mulberry leaves and on artificial diet. Journal of Proteome Research 7, 5103-5111.

Zhu, Y.C., Zeng, F., Oppert, B., 2003. Molecular cloning of trypsin-like cDNAs and comparison of proteinase activities in the salivary glands and gut of the tarnish plant bug Lygus lineolaris (Heteroptera: Miridae). Insect Biochemistry and Molecular Biology 33, 889-899.

Zito, E., Melo, E.P., Yang, Y., Wahlander, A., Neubert, T.A., Don, R., 2010. Oxidative protein folding by an endoplasmic reticulum-localized peroxiredoxin. Molecular Cell 40, 787-797. 